\title{
A Pragmatic Approach to Coping with Matrix Effects during ICP-MS Analysis of Trace Elements in Silicate Rocks and Calibration of REE Interferences
}

\author{
C. Michael B. Henderson ${ }^{1,2}$, Paul R. Lythgoe ${ }^{1}$, Karen J. Theis ${ }^{1}$ \\ ${ }^{1}$ School of Earth and Environmental Sciences (SEES), University of Manchester, Manchester, UK \\ ${ }^{2}$ ASTec, Sci-Tech Daresbury Laboratory, Science and Technology Funding Council, Warrington, UK \\ Email: michael.henderson@manchester.ac.uk
}

How to cite this paper: Henderson, C. M. B., Lythgoe, P. R., \& Theis, K. J. (2019). A Pragmatic Approach to Coping with Matrix Effects during ICP-MS Analysis of Trace Elements in Silicate Rocks and Calibration of REE Interferences. Journal of Geoscience and Environment Protection, 7, 82-125. https://doi.org/10.4236/gep.2019.73005

Received: January 10, 2019

Accepted: March 18, 2019

Published: March 21, 2019

Copyright ( 2019 by author(s) and Scientific Research Publishing Inc. This work is licensed under the Creative Commons Attribution International License (CC BY 4.0).

http://creativecommons.org/licenses/by/4.0/

(c) (i) Open Access

\begin{abstract}
Operating an Agilent 7700X ICP-MS spectrometer under robust plasma conditions $(1550 \mathrm{~W})$ with a He-filled octopole collision cell and analysing solutions ( $<2000 \mu \mathrm{g} \cdot \mathrm{g}^{-1}$ total dissolved solids) still suffered analyte peak suppression due to matrix effects. International reference rocks BCR-1, BHVO-1, AGV-1, G-2 and BCR-2 all showed count rate reductions for 36 elements (mass range ${ }^{7} \mathrm{Li}$ to ${ }^{238} \mathrm{U}$ ) averaging $\sim 10 \%$ but with no dependence on isotope mass. Use of an internal standard $\left({ }^{103} \mathrm{Rh}\right)$ and/or using a ten-fold dilution of sample solutions reduced these effects but problems with reduced count rates combined with larger errors for some elements introduced other problems. The best approach was to normalise the count rates for each element in the other samples against those for BCR-1 as an external standard; thus the count suppression due to the matrix effect is corrected for each individual element. This approach provides standardization "traceability" in line with the ERM ISO/IEC requirement. Experiments are also reported on quantifying the proportions of $\mathrm{Ba}$ and selected REE oxide/hydroxide components versus parent isotopes $(\mathrm{XO} / \mathrm{X}$ and $\mathrm{XOH} / \mathrm{X})$. This information is essential for correcting peak interferences on higher mass number REE for the rock samples, and equations are developed to use measured $\mathrm{CeO} / \mathrm{Ce}$ and $\mathrm{CeOH} / \mathrm{Ce}$ ratios to predict such values for any other member of the REE suite. Concentrations obtained show excellent agreement with recommended values for the international reference materials especially for the REE. Robust data are also provided for two other standard rocks: nepheline syenite STM-1 and quartz syenite CAAS-1; the latter shows exceptional enrichments of $\mathrm{Zr}$, REE, Th, and $\mathrm{U}$.
\end{abstract}




\section{Keywords}

ICP-MS, Dilution Minimises Matrix Effects, BCR-1 as an External

Standard, New Analyses for STM-1 and CAAS-1, Calibration of

$\mathrm{X}-\mathrm{O} / \mathrm{OH}$ Interferences on REE Elements

\section{Introduction}

In recent years Environmental and Earth Science research programmes have benefitted greatly from the application of Inductively Coupled Plasma Mass Spectrometric (ICP-MS) trace element analyses (Potts, 1987; Jenner et al., 1990; Linge \& Jarvis, 1997; Makishima \& Nakamura, 2006; Chauvel et al., 2010). Note that some laboratories use specialised procedures involving element separation, isotope dilution, micro-flow injection, or multi-stage internal standardisation (e.g., Makishima \& Nakamura, 2006). In a wide-ranging annual review of new atomic-spectrometry developments, Evans et al. (2018) include discussions of ICP-MS techniques that provide higher nebulization efficiencies and the ability to analyse slurries and suspensions of nanoparticles. Evans et al. (2018) also report the recent development of "triple Q (uadrupole)" techniques (ICP-QQQ-MS) aimed at further elimination of spectroscopic interferences. However, in a biennial review of key recent analytical developments, Linge et al. (2017) comment "Many fundamental aspects of ICP-MS are still only understood in a qualitative sense, despite some 40 years of research..."

The School of Earth and Environmental Sciences (SEES), University of Manchester, currently operates Agilent 7500cx and 7700x spectrometers fitted with octopole He collision cells (ORS) and high matrix introduction (HMI) accessories which ought to combine to reduce polyatomic/isobaric interferences and non-spectroscopic effects resulting from changes in plasma conditions and to element count rates being suppressed or enhanced depending on the nature of the matrix composition of the solutions being studied. The latter are known as "matrix effects". Most samples analysed currently are ground waters, rice grains and other "environmental" samples, or are nitric acid solutions prepared from the residues of HF acid digestion of terrestrial aluminosilicate rocks and meteorites which contain up to $1000-2000 \mu \mathrm{g} \cdot \mathrm{g}^{-1}$ of total dissolved solids (TDS; i.e. $0.1-0.2 \mathrm{wt} \%)$.

Over the years one of us $(\mathrm{CMBH})$ has carried out research on Li-mica granitic rocks from S.W. England which are enriched in "rare" elements typical of late-stage pegmatites (e.g. Li up to $2500 \mu \mathrm{g} \cdot \mathrm{g}^{-1}, \mathrm{Rb}$ and Cs up to 2000 and 200 $\mu \mathrm{g} \cdot \mathrm{g}^{-1}$, respectively, and B up to $1.5 \% \mathrm{w} / \mathrm{w}$ (Henderson et al., 1989). In an ongoing research programme we are studying a wide range of trace elements in sub-volcanic alkaline igneous rocks from the Marangudzi Ring Complex, Zimbabwe. Earlier XRF analyses of the Marangudzi rocks have shown that their alkali-rich character is reflected in very high concentrations of Sr (up to 6000 
$\mu \mathrm{g} \cdot \mathrm{g}^{-1}$ in nepheline syenites), $\mathrm{Ba}$ (up to $1.6 \% \mathrm{w} / \mathrm{w}$ in biotite syenogabbros), rare earth elements (REE; e.g., up to $600 \mu \mathrm{g} \cdot \mathrm{g}^{-1} \mathrm{Ce}$ in nepheline syenites), and $\mathrm{Zr}$ (up to $2000 \mu \mathrm{g} \cdot \mathrm{g}^{-1}$ in quartz syenites). Thus our analytical requirements cover a large range of minor and trace elements including relatively rare elements. Unpublished XRF analyses of powdered Marangudzi rock samples and isotopic analyses for Marangudzi rocks have already provided reliable isotope dilution data for ${ }^{87} \mathrm{Rb},{ }^{86} \mathrm{Sr},{ }^{147} \mathrm{Sm}$ and ${ }^{144} \mathrm{Nd}$ (Foland et al., 1993; Landoll, 1994) and such data provide a useful yardstick for assessing the reliability of the new ICP-MS data. Also analysed in this work were international standard reference materials United States Geological Survey (USGS) rocks BCR-1, BHVO-1, AGV-1, G-2, BCR-2, STM-1 and Canadian syenite CAAS-1). We will use the International Association of Geoanalysts terminology (www.geoanalyst.org/standard-reference-material/) to refer to these international rock "standards" as "reference materials".

In analyses carried out in 2017 we attempted to avoid using an internal standard but during data-reduction we found that the ICP-MS data for solutions having dilution factors (DF) of 500 (TDS $<2000 \mu \mathrm{g} \cdot \mathrm{g}^{-1}$ ) generally gave lower concentrations than those for the most reliable elements determined by XRF (e.g., $\mathrm{Ni}, \mathrm{Ba}, \mathrm{Ce}$ ) and ID (e.g., $\mathrm{Nd}, \mathrm{Sm}$ ) for the same Marangudzi rocks while the BCR-1, BHVO-1, AGV-1, and G-2 samples normalised to the recommended concentrations for most elements gave slightly lower ratios (e.g., REE $\sim 0.90 \pm$ $0.05)$ than expected. We also diluted all of these solutions by a further 10 times (final DF 5000 and $<100 \mu \mathrm{g} \cdot \mathrm{g}^{-1}$ TDS); the data for each set of samples were processed with and without being corrected using ${ }^{103} \mathrm{Rh}$ as an internal standard. We subsequently (September 2018) carried out further analyses: to check on the counting stability for the element suite including that for the Rh internal standard and to assess the efficiency of the washing procedure between rock analyses or batches of analyses. In 2017 we carried out experiments to calibrate corrections for spectral interferences of ${ }^{137} \mathrm{Ba}$-oxide molecular complexes on ${ }^{153} \mathrm{Eu}$ and of ${ }^{141} \mathrm{Pr}-\mathrm{O}$ and ${ }^{140} \mathrm{CeOH}$ on ${ }^{157} \mathrm{Gd}$ but in the latest analytical work we have studied a much wider range of possible molecular oxide and hydroxide interferences on REE analyses.

We present here our data for the various international reference rocks which have been studied using routine sample preparation and analytical procedures. We have concentrated mostly on comparing our results to the recommended values for the most reliable reference materials (BCR-1, BHVO-1, AGV-1, and G-2). We will assess the reliability of minimising matrix effects by: 1 ) normalising data using a Rh internal standard; 2) using the DF 5000 series rather than the more concentrated DF 500 samples, both with and without Rh standard correction; and 3) normalising our DF 500 data for the other international reference materials to those for BCR-1. Analytical data for basalt BCR-2 are provided and we have concentrated on obtaining reliable data for the nepheline syenite STM-1 and quartz syenite CAAS-1. We also present details on dealing with spectral interferences on certain members of the REE group of elements. Thus we aim is to 
establish as straightforward a protocol as possible for digesting, analysing and standardising trace element concentrations for mixed batches of rocks ranging from basaltic to alkali-, and trace-element-rich, under- and over-saturated igneous rocks without time-consuming chemical separations and multi-internal-standard corrections to deal with matrix effects. Whilst recently-developed ICP-QQQ-MS instrumentation (Evans et al., 2018; Balcaen et al., 2015) would undoubtedly provide more reliable data than ours, many laboratories still use older and serviceable spectrometers with collision cells (CC) and dynamic reaction cells (DRC) and we expect that such workers will find our approach highly relevant and useful.

\section{Sample Preparation, Analytical, and Data Reduction Procedures}

Rock powders were prepared for analyses in a general-purpose chemical analytical laboratory but the initial solutions (DF500) were diluted where necessary and analysed by ICP-MS in a class 1000 cleanroom.

\subsection{Sample Preparation in the General Purpose Laboratory}

About $100 \mathrm{mg}$ of each rock was weighed accurately, added to PFA microwave vessels and digested in $\mathrm{HF} / \mathrm{HNO}_{3}$ at $170^{\circ} \mathrm{C}$ in a MARS 5 Xpress (CEM Corporation) microwave. The total dissolved solid (TDS) content is $<0.2 \%\left(2000 \mu \mathrm{g} \cdot \mathrm{g}^{-1}\right)$ because $\mathrm{SiO}_{2}$ has been removed by the $\mathrm{HF}$ attack. Note that some laboratories use hydrofluoric/perchloric rather than HF/nitric acid attacks (Yokoyama et al., 1999; Makishima \& Nakamura, 2006) which would be expected to eliminate residual fluoride more efficiently; this, in turn, could have implications to analysing $\mathrm{REE}$ and $\mathrm{Zr} / \mathrm{Hf}$ in the same solution (e.g., Makishima et al., 2009). In addition, analysing solutions containing HF to prevent hydrolysis and precipitation of HFSE (Makishima et al., 2009; Tanaka et al., 2013) requires the use of equipment with an HF resistant sample introduction system. However, many other laboratories achieve reliable results with $\mathrm{HF} / \mathrm{HNO}_{3}$ digestion (Eggins et al., 1997; Robinson et al., 2006). In any case, health and safety regulations in our laboratories forbid the use of perchloric acid without approved wash-down fume-cupboard facilities which we lack, and our ICP-MS equipment cannot be used with HF-containing solutions. We will demonstrate that our analytical results for international standard rocks show that our sample preparation $\left(\mathrm{HF} / \mathrm{HNO}_{3}\right)$ and analytical methods are robust and reliable.

\subsection{Multi-Element Solution Standard Preparation}

The concentrated certified trace element standard solutions available to us in this work were those used in many projects involved with analysing trace elements in various environmental samples, mainly ground waters, rice samples and radiochemical samples. Thus we have used these standards without attempting to "matrix match" them by making up synthetic igneous rock matrices 
ranging from gabbros, to quartz and nepheline syenites. The three certified standard solutions used are: Alfa Aesar, Multi-element Plasma Standard Solution 4 (Specpure, Product number 42,885); VWR single element (certified \pm $0.5 \%$ ); and VWR Aristar $10 \mu \mathrm{g} \cdot \mathrm{g}^{-1}$ (certified $\pm 0.5 \%$ ) single element standard solutions. These were mixed to make serial dilutions $\left(1,5,10,50,100 \mathrm{mg} \cdot \mathrm{l}^{-1}\right)$. A "standard blank" ( $\left.2 \% \mathrm{w} / \mathrm{v} \mathrm{HNO}_{3}\right)$ was prepared at the same time, together with wash solutions (wash station 1: $\mathrm{NH}_{4} \mathrm{OH} / \mathrm{EDTA} / \mathrm{H}_{2} \mathrm{O}_{2}$ /Triton-X; and wash station 2: $2 \%$ each of $\mathrm{HNO}_{3} / \mathrm{HCl}$ ). All of these solutions were prepared fresh for every set of samples analysed.

\subsection{ICP-MS Equipment and Analytical Procedures Used in 2017}

The ICP-MS equipment used and the operating conditions for the analyses obtained during the period June to December, 2017 are summarized in Table 1.

Table 1. Instrument and operating conditions.

\begin{tabular}{|c|c|}
\hline 2017 instrument conditions & \\
\hline ICP System, quartz glass "torch" & Agilent 7700x ICP-MS \\
\hline RF forward power & $1550 \mathrm{~W}$ \\
\hline Frequency & $27.12 \mathrm{MHz}$ \\
\hline Depth sampled & $8 \mathrm{~mm}$ above load coil \\
\hline Plasma torch Ar gas flow rate & $15 \mathrm{~L} \cdot \min ^{-1}$ \\
\hline He collision cell, $\mathrm{ORS}^{3}$ & $4.5 \mathrm{~mL} /$ minute $\mathrm{He}$ when $\mathrm{ON}$ \\
\hline Kinetic energy discrimination of $\mathrm{ORS}^{3}$ & $4 \mathrm{~V}$ ED \\
\hline Autosampler & ASX-500 \\
\hline Sample uptake rate & $0.8 \mathrm{ml} / \mathrm{min}$ \\
\hline Peristaltic pump & $0.1 \mathrm{rps}$ \\
\hline Nebulizer & Concentric GE MicroMist \\
\hline Nebulizer (carrier) Ar gas flow & $1.0 \mathrm{~L} \cdot \mathrm{min}^{-1}$ \\
\hline Auxiliary (make-up) gas flow & $0.1 \mathrm{~L} \cdot \min ^{-1}$ \\
\hline Spray chamber & $\begin{array}{c}\text { Scott double pass, quartz glass, } \\
\text { Peltier pump, } 2^{\circ} \mathrm{C}\end{array}$ \\
\hline Ni sampler cone orifice & $1.0 \mathrm{~mm}$ \\
\hline Ni skimmer cone orifice & $0.7 \mathrm{~mm}$ \\
\hline External-1 lens voltage & $0 \mathrm{~V}$ (to improve stability) \\
\hline Detector & Electron multiplier \\
\hline Data collection; 3 scans through mass range per sample & Analyte peak jump mode \\
\hline Total acquisition time per sample excluding wash & $75.56 \mathrm{~s}$ \\
\hline Each mass, 3 points 0.25 amu apart; Dwell time $0.1 \mathrm{~s}$ & $0.3 \mathrm{~s}$ \\
\hline Peak width at half height & $\sim 0.7 \mathrm{amu}$ \\
\hline $\mathrm{CeO} / \mathrm{Ce}$ and $\mathrm{Ce}^{2+} / \mathrm{Ce}^{+}$ & $1.35 \%$ and $1.32 \%$ \\
\hline \multicolumn{2}{|l|}{2018 data collection differences } \\
\hline Data collection; 10 scans through mass range per sample & Analyte peak jump mode \\
\hline Total acquisition time per sample excluding wash & $75.56 \mathrm{~s}$ \\
\hline $\mathrm{CeO} / \mathrm{Ce}$ and $\mathrm{Ce}^{2+} / \mathrm{Ce}^{+}$ & $0.45(5) \%$ and $0.97(9) \%$ \\
\hline
\end{tabular}


Note that the He collision cell (Wilbur, 2007) was pressurised with He to minimise the possibility of polyatomic, molecular interferences including those involving $\operatorname{Ar}$ (see Linge \& Jarvis, 1997). Before each analytical run the 7700x spectrometer was "tuned" following the standard Agilent procedure. The operation of the plasma followed the "Robust" procedure and settings were chosen that stabilised the operating conditions even though the sensitivity was decreased by a factor of 2 to 3 . We also ran standard solutions of $\mathrm{Zr}, \mathrm{Ba}$, and Pr samples to determine the oxide/element ratios and/or doubly charged cation proportions.

The as-prepared sample solutions were taken and the same routine was used for each: 45 second sample uptake; $10 \mathrm{sec}$ stabilisation; $5 \mathrm{sec}$ for collision cell to stabilise; $5 \mathrm{sec}$ wash routine $\left(2 \% \mathrm{w} / \mathrm{v} \mathrm{HNO}_{3}\right) ; 5 \mathrm{sec}$. in wash station 1; and $5 \mathrm{sec}$ in wash station 2. Using two peristaltic pump windings, a $1 \mathrm{mg} \cdot \mathrm{l}^{-1} \mathrm{Rh}$ internal standard solution in $2 \% \mathrm{HNO}_{3}$ was mixed with the sample/standard/wash solution in a mixing chamber; exactly the same Rh solution was constantly pumped into each sample, standard or wash solution.

In the initial stages, analysis of rock digests having dilution factors of 500 (DF500) were carried out in batches of 12 samples (11 rocks and one procedural blank) with sets of solution standards run before and after each batch of 'unknown' samples so that machine stability could be assessed. Wash routines were run and count rates monitored immediately after each concentrated standard analysis. Subsequently it was decided to dilute the samples by a factor of 10 (to DF 5000) to assess whether this reduced matrix effects. The DF 500 solutions were diluted off-line using $2 \% \mathrm{HNO}_{3}$. The total time for each analytical run varied from $\sim 4$ hours (run 6717, June 2017; 5 sets of blanks, standards, and washes and 4 sets of rock digests) to $\sim 1$ hour (run 5917, September 2017; 2 sets of blanks, standards, washes and 1 set of rock digests).

\subsection{Calculation of Element Concentrations from ICP-MS Peak Intensities and Dealing with Errors}

Initial concentrations were obtained with Mass Hunter workstation B.01.01 Agilent commercial software using linear fits, blank offset origin, no weighting, and normalising to a ${ }^{103} \mathrm{Rh}$ internal standard. Initial concentrations were provided as $\mu \mathrm{g} . \mathrm{l}^{-1}$ concentrations with no correction for either drift or peak interferences resulting from doubly charged cations or molecular interferences from oxides. Final concentrations in $\mu \mathrm{g} \cdot \mathrm{g}^{-1}$ were obtained off-line taking account of rock sample masses and dilution factors used and were corrected for machine drift using a linear correction to normalise data back to the initial standard count rates; drift was commonly $<1 \%-2 \%$. Element isotope interferences were identified based on published studies as follows: ${ }^{45} \mathrm{Sc}$ (doubly charged ${ }^{90} \mathrm{Zr}$ (Townsend, 2000; Pretorius et al., 2006); molecular $\left({ }^{28} \mathrm{Si}^{16} \mathrm{O}^{1} \mathrm{H}\right)$ Robinson et al., 2006)), ${ }^{69} \mathrm{Ga}$ (doubly charged ${ }^{138} \mathrm{Ba}$ Longerich et al., 1990), ${ }^{153} \mathrm{Eu}$ (molecular $\left({ }^{137} \mathrm{Ba}^{16} \mathrm{O}^{+}\right)$), ${ }^{157} \mathrm{Gd}(\mathrm{mo}-$ lecular $\left({ }^{141} \operatorname{Pr}^{16} \mathrm{O}^{+}\right)$(Jenner et al., 1990; Robinson et al., 2006)).

Potential errors associated with count rates for the element suite in standards 
and samples must also be assessed, in particular those for ${ }^{103} \mathrm{Rh}$ as its use for internal standardisation would impact all of the other elements being studied. The count rates for ${ }^{103} \mathrm{Rh}$ are sufficiently well defined to have theoretical counting errors (square root of counts $\sqrt{ } \mathrm{N}$ for a "normal" distribution) of $\sim 0.03 \%$ but the measured cps show fluctuations for adjacent samples and standard solutions. However, ${ }^{103} \mathrm{Rh}$ counts for rock sample solutions analysed in 2017 tended to be $\sim 10 \%$ smaller than those for all standard-solution/blanks reflecting the higher TDS in the former. The ${ }^{103} \mathrm{Rh}$ count rate RSDs (as \%) average $\sim 1 \%-2 \%$ for the standard solutions, those for the rock samples average $\sim 4 \%$; values for adjacent analyses of the same reference rock digest sometimes show variations of $\sim 4 \%$ $5 \%$. Note that these variations occur even though the Rh solution is being continuously pumped for all samples in the same run. Similar results were found for our 2018 experiments (run 6918) where 10 identical BCR-1 solutions prepared from a single 2017 sample preparation (DF500 used in experiment 5917) were studied. Thus, it seems that an intrinsic counting error of $\sim 4 \%$ associated with our ICP-MS rock analyses is likely to reflect transient, periodic fluctuations in either or all of the sample introduction, plasma operation, ion transfer path, or mass spectrometer/detector system. Note that plasma/instrumental "flicker noise" contributes to such errors (Baxter et al., 2012).

It is necessary to take account of the accumulation of errors by propagating the peak count rate RSD \% values to assess the resulting effect of combining standard and sample solution count rates to obtain concentrations directly for each element, as well as in the use of ${ }^{103} \mathrm{Rh}$ internal standardisation and also with external standardisation using BCR-1 data for DF500 solutions. We illustrate here the scale of the errors by referring to averages for different composition standards for one batch of reference sample solutions (3 BCR-1, 3 BHVO-1, 2 AGV-1, 2 G-2 and one STM-1 sample). The count rate RSD errors show similar values across the rock suite. Propagated errors are calculated from the mean RSD data obtained by combining averages of count rates for each element in the solution standards (denoted $\overline{\mathrm{A}}$, average of 10 standard solution count rates) with those for the average sample suite (denoted $\bar{B}$, average of 11 rock samples) as follows:

$$
(\operatorname{RSD} \%)=\sqrt{\frac{\overline{\mathrm{A}}^{2}}{10}+\frac{\overline{\mathrm{B}}^{2}}{11}}
$$

The equivalent propagated error for using $\mathrm{Rh}$ as an internal standard (RSD) $\mathrm{Rh}$ would involve using 4 terms, i.e., $\overline{\mathrm{A}}, \overline{\mathrm{B}}$, average Rh RSD for solution standards (denoted $\bar{C}$ ) and average Rh RSD for sample solutions (denoted $\bar{D}$ ):

$$
(\operatorname{RSD} \%)=\sqrt{\frac{\overline{\mathrm{A}}^{2}}{10}+\frac{\overline{\mathrm{B}}^{2}}{11}+\frac{\overline{\mathrm{C}}^{2}}{10}+\frac{\overline{\mathrm{D}}^{2}}{11}}
$$

To save space we do not show the full set of data for the 36-element suite but to summarise, the propagated errors for peak counts measured for DF500 solutions without internal standard corrections are $<2 \%$ (relative standard error, 
RSE) for $\mathrm{Li}, \mathrm{Be}, \mathrm{B}$ and $\mathrm{Sc},<0.4 \%$ for $\mathrm{V}$ and $\mathrm{Cr}$ and $<0.25 \%$ for the other elements including all the REE. For the DF500 solution corrected for the internal standard $(\mathrm{Rh})$ the lightest element errors are similar to the values given above but are 5 times larger for all the other elements because the latter values are calculated for two more variables (i.e. plus average $\mathrm{Rh}$ in standard counts and $\mathrm{Rh}$ in sample counts). The higher errors for the lightest elements ( $\mathrm{Li}, \mathrm{Be}, \mathrm{B})$ clearly result from their lower count rates.

In this work it has been essential to assess the quality of our analytical data against the published recommended values and we have, therefore, followed the GeoPT Proficiency Testing approach advocated by Potts et al. (2013) and Jochum et al. (2015). The expected standard deviation varies as function of concentration level according to the seminal work of Horwitz (e.g., Horwitz \& Albert, 1995; Albert \& Horwitz, 1997). To fit in with the approach of Potts et al. (2013) we used the equation of the form:

$$
h_{a}=10^{6}\left(k X_{a}^{0.8495}\right)
$$

where $h_{a}$ is the Horwitz "target standard deviation", $k=0.01$ for pure geochemistry laboratories, $X_{a}$ is the recommended standard rock fractional concentration for each element, and the multiplication by $10^{6}$ is necessary to express the standard deviation in terms of the conventionally used $\mu \mathrm{g} \cdot \mathrm{g}^{-1}$ concentrations. These values for each element in each rock analysed can then be used to calculate $Z$ scores using the equation:

$$
z=\frac{\left(X-X_{a}\right)}{h_{a}}
$$

where $X$ is our average data for the sample and $X_{a}$ is the recommended concentration, both in $\mu \mathrm{g} \cdot \mathrm{g}^{-1}$ units. Based on the ISO and GeoPT guidelines, accepted analyses must have $z$ scores falling within the limits $z=+2$ to -2 .

Finally, we have assessed whether the difference $\Delta=\left(X-X_{a}\right)$ is significant by propagating uncertainty errors following Linsinger (2010) using the equation:

$$
U_{\Delta}=2 \sqrt{u_{m}^{2}+u_{C R M}^{2}}
$$

where $U_{\Delta}$ is the expanded uncertainty, $u_{m}$ is our measured standard deviation divided by the square root of the number of determinations, and $u_{C R M}$ is the quoted uncertainty divided by 2 ; the calculated values correspond to a confidence level of $95 \%$. To simplify the use of such values for different elements we will convert average $U$ values for the different samples studied to \%RSE values.

\subsection{Analytical Procedures Used in 2018}

After assessing all of the data obtained, preparing an initial version of this paper, and after considering comments from experienced ICP-MS analysts we carried out further analyses in September 2018. This new work followed episodes of equipment cleaning and servicing of the Agilent 7700x spectrometer; see Table 1 
for the differences in operating conditions used in the later experiments. Results for two sets of experiments were obtained: the first aimed at obtaining data for possible spectral interferences of divalent ${ }^{90} \mathrm{Zr}$ on ${ }^{45} \mathrm{Sc},{ }^{138} \mathrm{Ba}$ and ${ }^{138} \mathrm{Ce}$ on ${ }^{69} \mathrm{Ga}$, ${ }^{142} \mathrm{Ce}$ and ${ }^{142} \mathrm{Nd}$ on ${ }^{71} \mathrm{Ga}$, and of ${ }^{144,148} \mathrm{Nd}$ on ${ }^{72,74} \mathrm{Ge}$; and the second to obtain further information to correct for possible interferences between oxide and hydroxide complexes for Ba and REE species on REE analyte peaks at mass numbers 16 or 17 higher than the interfering elements. In order to study the relationship between $\mathrm{X}-\mathrm{O}$ bond-strength and/or ionisation potential we also studied Cs and Th solutions. In the first experiment, for each mass number studied, 10 sweeps were carried out and each count was recorded to assess count rate stability for each mass number. The main isotope peaks had $\%$ RSD values $<1 \%$ although some of the weaker $(\mathrm{X}-\mathrm{OH})$ molecular peaks had RSD values higher than $10 \%$. Average CPS values were used to calculate percentage values for $\mathrm{X}^{2+} / \mathrm{X}^{+}$and for $\left(\mathrm{X}^{16} \mathrm{O}\right) / \mathrm{X}$ and $\left(\mathrm{X}^{16} \mathrm{O}^{1} \mathrm{H}\right) / \mathrm{X}$ interferences.

The purpose of the other experiment was to assess: 1) how the equipment sensitivity might have changed between analyses carried out in September 2018 and those obtained throughout $2017 ; 2$ ) to assess the count rate stability for each mass number through the mass range 7 to $238 \mathrm{amu}$. Samples run included: 10 repeat reagent blanks; 10 repeat standard solutions (each $50 \mathrm{ng} \cdot \mathrm{g}^{-1}$ ); 10 repeat analyses of ONE of the BCR-1 digestion solutions which was first studied in September 2017; and two repeats each of 3 different Marangudzi samples (initially analysed in June 2017) chosen for their high concentrations of $\mathrm{Ba}$ and REE. These additional analyses of rock sample solutions prepared and first analysed in 2017 (DF 500), together with 3 of the original procedural blanks were carried out on the original solutions further diluted to DF1000. In addition, Rh as an internal standard was added to all solutions to the same concentration level as used in 2017. Solutions were run in the order: 10 consecutive blanks, 10 consecutive standards, 4 wash samples, procedural blank 5917/1, 10 consecutive BCR-1 solutions (DF1000), 3 Marangudzi samples (DF1000), procedural blanks 6717/1, and $3 \mathrm{Ce}$ standard solutions $\left(100 \mathrm{ng} \cdot \mathrm{g}^{-1}\right)$ to calibrate $\mathrm{Ce}^{2+} / \mathrm{Ce}$ and $\mathrm{CeO} / \mathrm{Ce}$ ratios, and then 4 washes. A repeat set of these solutions was run followed by $5 \times 2 \% \mathrm{HNO}_{3}$ blanks (no Rh added) to check whether any of the elements studied showed significantly higher concentrations than for the initial blanks analysed. The total run time was 8.5 hours and initial study of count rates suggested a maximum degree of drift of $<4 \%$ which was corrected for assuming a linear trend with time. Inspection of the 10 count rates obtained during the multiple sweeps through the mass range showed that no anomalous ("rogue") count rate excursions had occurred for the blanks, standard solutions, and rock digests. Mean \% RSD values for all elements in individual samples of standard solutions were uniformly $<1 \%$; those for individual BCR-1 solutions were normally $<2 \%$ and for the Marangudzi samples were normally $<2.5 \%$. However, adjacent analyses for the same rock digest showed RSD variations up to $\sim 4 \%$ (see above). 
The ICP-MS counting sensitivity across the mass range for the 2018 analyses shows some differences compared to those experienced using the same spectrometer in 2017 with the lightest ( $\mathrm{Li}, \mathrm{Be}$, and B) and heaviest isotopes ( $\mathrm{La}$ to $\mathrm{U}$ ) having similar sensitivities for data for both years but with the medium mass range isotopes having count rates for 2018 experiments about half of those for 2017.

\section{International Reference Rocks and Characterization of Non-Spectroscopic Interferences}

\subsection{Recommended Values for Standard Rocks}

The recommended values we have used for BCR-1, BHVO-1, and AGV-1 for all elements except the first transition series (3d) elements are the "preferred" values from Jochum et al. (2015) (cf. GeoReM data for 2016); for the 3d transition elements we prefer to use the high-mass resolution, magnetic sector data of Townsend (2000) rather than lower resolution quadrupole MS data which might be vulnerable to polyatomic interferences. The USGS standard nepheline syenite STM-1 has been studied less thoroughly than other international rock standards and our adopted values were based on the compilations of Gladney \& Roelandts (1988) and Govindaraju (1994) supplemented by later published ICP-MS (Korotev, 1996; Dai-Kin et al., 1998; Gouveia \& Prudêncio, 2000; Bédard \& Barnes, 2002; Alnour et al., 2015) and INAA data (Dai-Kin et al., 1998; D’Orazio, 1998; Panteeva et al., 2003; Smirnova et al., 2003; Pi et al., 2014); the REE data provide the most reliable analyses. Quartz syenite CAAS-1 has been little studied since its original issue and our adopted data are mainly those of Sine et al. (1969) with a few later values: Sc, Co, Y, Yb, V (Hofmeyr, 1972); V (Fuge, 1973); Co, Cr, Cu, $\mathrm{Ni}, \mathrm{Sr}, \mathrm{Zn}$ (Brooks et al., 1985). Averages for these values for STM-1, together with those for quartz syenite CAAS-1 and BCR-2 (Jochum et al., 2015) are dealt with in Section 4.6.2.

\subsection{Coping with Non-Spectral Analytical Problems (Matrix Effects)}

The last 30 years has shown a huge increase in publications reporting the application of ICP-MS techniques to the analysis of geological and environmental materials. In addition much fundamental work has been carried-out on dealing with non-spectroscopic matrix effects (e.g., Agatemor \& Beauchemin, 2011). The brief review here will be restricted to factors that we have exploited to optimise the reliability of our analytical approach.

It has been generally accepted that an optimum total dissolved solids (TDS) concentration for rock digests to be analysed by conventional ICP-MS methods should have dilution factors (DF) of $\sim 500$ - 1000 or a maximum TDS $0.1 \%$ 0.2\% (1000 - $\left.2000 \mu \mathrm{g} \cdot \mathrm{g}^{-1}\right)$ (e.g., Potts, 1987; Jenner et al., 1990; Eggins et al., 1997; Makishima et al., 1997; Jarvis, 1988; Willbold et al., 2003; Agilent, 2005; Ardini et al., 2010). Analysing these solutions using enriched isotope or bulk element 
internal standards (e.g., In, Rh) would be expected to give reliable results corrected for machine drift and matrix effects. However, some researchers have used specialised equipment in an attempt to minimise the latter effects. Thus, Makishima \& Nakamura (1997) used high power plasma operating conditions and flow injection to show that more concentrated solutions analysed without using an internal standard gave results for BCR-1 mainly within $2 \%$ of the recommended values although their results for AGV-1 were generally up to 5\% higher than the recommended values (see later, Section 4.5). Lin et al. (2000) developed a "simple method" using rock digests with DF $=2000$ and concluded that overcoming matrix-effects was best managed by using more dilute solutions.

Yokoyama et al. (2016) reported the results for key experiments carried out to quantify the optimum DF used and to assess the suitability of internal standard species, mainly using enriched isotopes and isotope dilution standardisation methods. They showed that synthetic basalt solutions having DF values $>$ 2000 showed no decrease in sensitivity. Tan and Horlick (1987) reported that heavy matrix elements caused the most serious matrix effects (generally analyte intensity suppression) and that light analyte elements were more seriously affected than heavier ones. In addition, easily ionised matrix elements (i.e., lower first ionization potentials, FIP) caused more serious matrix effects than those elements with higher FIP. Olesik and Jiao (2017) used later generation equipment to study how a range of 8 matrix elements (varying in mass from $\mathrm{Na}$ to $\mathrm{Tl}$ ) affected the change of sensitivity of 14 analyte elements (varying mass from Li to U). Overall, for different internal standards the correction appears to be broadly similar across the analyte mass range but note that the recovery magnitude for each IS tends to fluctuate (i.e., higher or lower values for adjacent elements in their Table 2) for elements of similar mass and FIP. Olesik and Jiao (2017) comment that with a single internal standard "recoveries were within $10 \%-20 \%$ for most analytes, regardless of mass". This seems to us to be an uncomfortably large fluctuation which is not simply related to mass or FIP but these values are in line with the precision quoted by Lin et al. (2000) and Yokoyama et al. (2016). We conclude that there is a tendency for ICP-MS data to be associated with an intrinsic, relative error of up to $\pm 5 \%$ which it is difficult to attribute to a particular matrix-effect mechanism; this value is at the upper end of the predicted overall precision experienced for ICP-MS analyses (e.g., 2\% - 5\%, Linge \& Jarvis, 1997); 2\% - 4\% for REE using medium resolution MS and isotope dilution standardisation (Robinson et al., 2006); an average of $\pm 5 \%$ for 86 rock standards, Dulski (2001); and mainly $\pm 2 \%-3 \%$ for isotope dilution standardisation with a few values up to $\sim 6 \%-8 \%$, Willbold et al. (2003). The overall precision estimates for our lower resolution quadrupole MS analyses for a wide range of elements compare favourably with higher mass resolution, ID calibrated analyses and clearly fall within this reliability range. 
Table 2. Representative count data (cps) from experiment 6918 (2018) for first blank and last wash solutions; apparent element contents for the first blank; the concentration change between first blank and last wash solutions; and \% errors associated with these changes compared to a DF1000 BCR-1 solution. Also included (RHS column) are "contamination" estimates (\%) from experiment 6717 based on progressively increasing blank count rates compared to element count rates in BCR-1.

\begin{tabular}{|c|c|c|c|c|c|c|}
\hline \multirow[b]{2}{*}{$\begin{array}{l}\text { Isotope } \\
\text { used }\end{array}$} & \multicolumn{5}{|c|}{ Experiment 6918 (2018) } & \multirow{2}{*}{$\begin{array}{c}\text { Expt. } 6717 \text { (2017) } \\
\text { \% "Contamination" increase in } \\
\text { Std solution blanks compared } \\
\text { to element conc. in BCR1 }\end{array}$} \\
\hline & $\begin{array}{c}\text { First blank } \\
\text { CPS }\end{array}$ & $\begin{array}{c}\text { First blank } \\
\text { ng.g }\end{array}$ & $\begin{array}{l}\text { Last wash } \\
\text { CPS }\end{array}$ & $\begin{array}{l}\text { Last wash-first blank } \\
\text { Apparent conc. } \\
\text { increase } \mathrm{ng} \cdot \mathrm{g}^{-1}\end{array}$ & $\begin{array}{l}\text { Equivalent } \\
\% \text { increase } \\
\text { vs BCR1 }\end{array}$ & \\
\hline${ }^{7} \mathrm{Li}$ & 39 & 0.3145 & 14 & -0.203 & -1.464 & 0.5 \\
\hline${ }^{9} \mathrm{Be}$ & 0 & 0.0012 & 2 & 0.009 & 0.661 & 0.01 \\
\hline${ }^{11} \mathrm{~B}$ & 186 & 2.2120 & 219 & 0.391 & 5.597 & 5 \\
\hline${ }^{45} \mathrm{Sc}$ & 28 & 0.0054 & 120 & 0.018 & 0.047 & - \\
\hline${ }^{51} \mathrm{~V}$ & 583 & 0.0424 & 1038 & 0.033 & 0.006 & 0.5 \\
\hline${ }^{53} \mathrm{Cr}$ & 284 & 0.1340 & 358 & 0.035 & 0.276 & 3 \\
\hline${ }^{59} \mathrm{Co}$ & 2215 & 0.0743 & 787 & -0.048 & -0.112 & 0.1 \\
\hline${ }^{60} \mathrm{Ni}$ & 1792 & 0.2299 & 1376 & -0.053 & -0.487 & - \\
\hline${ }^{63} \mathrm{Cu}$ & 4660 & 0.2152 & 5439 & 0.036 & 0.207 & 0.6 \\
\hline${ }^{66} \mathrm{Zn}$ & 1790 & 0.4508 & 2073 & 0.071 & 0.044 & - \\
\hline${ }^{85} \mathrm{Rb}$ & 210 & 0.0236 & 620 & 0.046 & 0.083 & 0.3 \\
\hline${ }^{88} \mathrm{Sr}$ & 287 & 0.0240 & 1291 & 0.084 & 0.019 & 0.01 \\
\hline${ }^{89} \mathrm{Y}$ & 1491 & 0.0473 & 473 & -0.032 & -0.093 & 0.01 \\
\hline${ }^{90} \mathrm{Zr}$ & 1287 & 0.0602 & 3563 & 0.106 & 0.041 & 0.05 \\
\hline${ }^{93} \mathrm{Nb}$ & 2465 & 0.0552 & 6900 & 0.099 & 0.667 & 1 to 5 \\
\hline${ }^{133} \mathrm{Cs}$ & 301 & 0.0116 & 567 & 0.010 & 0.906 & 1 \\
\hline${ }^{137} \mathrm{Ba}$ & 1237 & 0.1305 & 2697 & 0.154 & 0.034 & 0.02 \\
\hline${ }^{139} \mathrm{La}$ & 2582 & 0.0365 & 2720 & 0.002 & 0.007 & 0.03 \\
\hline${ }^{140} \mathrm{Ce}$ & 38054 & 0.4407 & 26967 & -0.128 & -0.210 & 0.03 \\
\hline${ }^{141} \mathrm{Pr}$ & 424 & 0.0049 & 839 & 0.005 & 0.070 & 0.03 \\
\hline${ }^{146} \mathrm{Nd}$ & 228 & 0.0154 & 317 & 0.006 & 0.019 & 0.02 \\
\hline${ }^{147} \mathrm{Sm}$ & 19 & 0.0016 & 93 & 0.006 & 0.077 & 0.01 \\
\hline${ }^{153} \mathrm{Eu}$ & 45 & 0.0008 & 334 & 0.005 & 0.253 & 0.004 \\
\hline${ }^{157} \mathrm{Gd}$ & 204 & 0.0076 & 321 & 0.004 & 0.052 & 0.03 \\
\hline${ }^{159} \mathrm{~Tb}$ & 48 & 0.0003 & 760 & 0.005 & 0.500 & 0.001 \\
\hline${ }^{163} \mathrm{Dy}$ & 14 & 0.0004 & 211 & 0.006 & 0.095 & 0.05 \\
\hline${ }^{165} \mathrm{Ho}$ & 49 & 0.0003 & 781 & 0.005 & 0.424 & 0.005 \\
\hline${ }^{166} \mathrm{Er}$ & 16 & 0.0003 & 262 & 0.005 & 0.146 & 0.05 \\
\hline${ }^{169} \mathrm{Tm}$ & 68 & 0.0004 & 930 & 0.005 & 1.130 & 0.005 \\
\hline${ }^{172} \mathrm{Yb}$ & 15 & 0.0004 & 208 & 0.006 & 0.171 & 0.03 \\
\hline${ }^{175} \mathrm{Lu}$ & 24 & 0.0002 & 498 & 0.005 & 0.982 & 0.05 \\
\hline${ }^{178} \mathrm{Hf}$ & 551 & 0.0141 & 2000 & 0.037 & 0.706 & 0.02 \\
\hline${ }^{181} \mathrm{Ta}$ & 3250 & 0.0162 & 3391 & 0.001 & 0.095 & 0.1 \\
\hline${ }^{208} \mathrm{~Pb}$ & 6873 & 0.1002 & 8335 & 0.021 & 0.142 & - \\
\hline${ }^{232} \mathrm{Th}$ & 2052 & 0.0167 & 3695 & 0.013 & 0.239 & 0.5 \\
\hline${ }^{238} \mathrm{U}$ & 2069 & 0.0131 & 3248 & 0.007 & 0.569 & 0.5 \\
\hline
\end{tabular}




\section{Results and Discussion}

\subsection{Count Rates for Standard Solution Blanks, Wash Solutions, and Procedural Blanks}

The ultra-low detection limits for trace elements shown by ICP-MS techniques means that most geochemically important elements can be detected in almost all laboratory prepared standard solution "blanks", even those prepared under "clean-lab" conditions. We find that wash solution and procedural blanks are commonly up to 2 to 3 times higher than the standard solution blanks. Contamination from DIW and distilled acids should be effectively constant on a given day but airborne dust contamination is likely to be random, particularly for the procedural blanks, which would introduce uncertainty in the analytical values for some elements at least. Thus, to put such data into context, the element concentrations in the procedural blanks calculated as a percentage of the concentrations of the same elements in BCR-1 average $\sim 1 \%-2 \%$ for the low mass numbers including $3 \mathrm{~d}$ elements, $<0.1 \%$ for the medium mass elements $\mathrm{Rb}$ to $\mathrm{Zr}$ and $<0.03 \%$ for the heavier elements including the REE. The exceptions are B (30\%), $\mathrm{Pb}(<5 \%)$ and $\mathrm{U}(\sim 1 \%)$. Note that high backgrounds for $\mathrm{Cu}$ and $\mathrm{Zn}(\sim 2 \%)$ are mainly from the DIW and $2 \%$ nitric acid solutions; however, significant $\mathrm{Zn}$ contamination from protective gloves has been reported (Garçon et al., 2017) and it is likely that the main $\mathrm{Zn}$ contamination ultimately comes from handling equipment and samples when wearing nitrile protective gloves. The possible errors for B are exceptionally high $(\sim 30 \%)$ which might be related to the possibility of B "sticking" to glassware surfaces (Linge \& Jarvis, 1997) but it is clear that the very low sensitivity for B makes it particularly prone to error. Procedural blanks for $\mathrm{Pb}$ are particularly variable consistent with random influx of dust particles in an old building close to a busy highway.

To consider whether significant contamination due to "memory" effects occurred after spraying high concentration solutions we have used count data for experiments 6717 and 5917 to assess possible "contamination" of wash solutions sprayed immediately after the highest concentration standard solutions. This approach is similar to that reported by Robinson et al. (2006) who also stressed the importance of rinse solutions having the same acidity as sample solutions $\left(2 \% \mathrm{v} / \mathrm{v} \mathrm{HNO}_{3}\right)$. We found that the $\sim 3$ minute "wash" procedure used immediately after spraying the $100 \mathrm{ng} \cdot \mathrm{g}^{-1}$ standard solutions reduces the count rates to $<0.01 \%$ of that for the standard for the REE, to $<0.01 \%$ for $\mathrm{Rb}, \mathrm{Sr}, \mathrm{Zr}, \mathrm{Nd}$ etc., to $<0.5 \%$ for $3 \mathrm{~d}$ elements, and $\mathrm{Li}$, and to $1 \%-2 \%$ of that for the $100 \mathrm{ng} \cdot \mathrm{g}^{-1}$ standard for B. For experiment 6717 we also assessed whether any progressive increase in standard solution blanks during the 8-hour-long experiment might be due to carry-over contamination ("memory effect"). Significant possible contamination compared to the element concentration in BCR-1 (reported as \%) was only found for $\mathrm{B}(5 \%), \mathrm{Cr}(3 \%)$, and $\mathrm{Nb}(1 \%-5 \%)$, see right hand column in Table 2 for the full data set. Note that the high field strength element $\mathrm{Nb}$ is known to show "memory" effects in ICP-MS analyses (e.g., Robinson et al., 2006). We 
confirmed these findings (experiment 6918) with Table 2 columns 2 and 3 showing average count rates for the first run of blanks and concentrations, respectively. Columns 4 and 5 show the average data for the last wash (after the last $50 \mathrm{ppb}$ standards, $\sim 6$ hours after the first blanks) and any concentration change compared to that for the first blanks can be assessed; thus the concentration increases compared to the element average for the BCR-1 data (column 6) are uniformly small except that for B (5.5\%). The progressive increase for $\mathrm{Nb}$ for this experiment might reflect some carry-over contamination but the amount relative to BCR- 1 is still $<1 \%$.

We conclude that these data show that, overall, the presence of element contaminants in both standard solution blanks and procedural blanks would have little effect on the reliability of rock sample data. In addition, the lack of significant carry-over contamination during prolonged analytical runs confirms that our ICP-MS analytical procedures are robust.

\subsection{Dilution Factors and Estimated Mean First Ionization Potentials (FIPs), Mean Atomic Masses (AM) and X-O Bond Strengths for Cations in the As-Prepared Rock Digests}

It is clear from published work that the concentration of TDS in the analysed solutions should be less than $0.1 \%-0.2 \% \mathrm{w} / \mathrm{w}\left(1000-2000 \mu \mathrm{g} \cdot \mathrm{g}^{-1}\right)$. In addition, the behaviours of different analyte elements in the Ar plasma, in the solution path, and in the mass spectrometer are influenced by the FIPs and isotope masses of the matrix element assemblage, particularly the properties of the major elements. Although the different standard rock types studied here are very different mineralogically and petrologically, this does not mean that the mean FIPs are distinct. Indeed, using the recommended major and minor element data for the original rocks (Jochum et al., 2015) the estimated mean FIP values for the cations are little different for the basalts, andesites and granites at $7.3 \pm 0.05 \mathrm{eV}$ with a slightly lower value of $7.0 \mathrm{eV}$ for the nepheline syenites. For the Si-free major and minor components remaining after the HF acid digestion the values in the analysed solutions are as follows:

\begin{tabular}{cccccc}
\hline & $\begin{array}{c}\text { Cation TDS } \\
\left(\mu \mathrm{g} \cdot \mathrm{g}^{-1}\right)\end{array}$ & $\begin{array}{c}\text { TDS }(\mathrm{Na}+\mathrm{K}) \\
\mu \mathrm{g} \cdot \mathrm{g}^{-1}\end{array}$ & $\begin{array}{c}\text { Mean cation } \\
\text { FIP, eV }\end{array}$ & $\begin{array}{c}\text { Mean AW } \\
\text { cations }\end{array}$ & $\begin{array}{c}\text { Mean } X \text {-O } \\
\text { bond strength } \\
\mathrm{kJ} \cdot \mathrm{mol}^{-1}\end{array}$ \\
\hline $\begin{array}{c}\text { Si-free rock } \\
\text { digest } s\end{array}$ & & & & & \\
BCR-1 & 602 & 78 & 6.41 & 36.4 & 431 \\
BHVO-1 & 684 & 42 & 6.61 & 36.7 & 444 \\
AGV-1 & 503 & 112 & 6.06 & 32.7 & 425 \\
G-2 & 383 & 134 & 5.74 & 30.7 & 406 \\
STM-1 & 495 & 204 & 5.69 & 29.7 & 385 \\
CAAS-1 & 539 & 92 & 6.29 & 35.8 & 415 \\
BCR-2 & 609 & 77 & 6.45 & 36.7 & 432 \\
\hline
\end{tabular}


As expected, the TDS in the basalt solutions is significantly higher than those for the granites; the andesite and syenites have intermediate values. Mean FIP values for the TDS components are distinctly higher for the basalts $(\sim 6.5 \mathrm{eV})$, intermediate for the andesite $(6.1 \mathrm{eV})$, and significantly lower for the granites and nepheline syenites $(\sim 5.6 \mathrm{eV})$. Of course, the lower values for the felsic rocks mainly reflect the higher concentrations of major element alkalis (see concentrations for $\mathrm{Na}+\mathrm{K}$ above). Also, based on published findings that analyte peak intensity suppression is greater for more easily ionised matrices, it is possible that the matrix effects for granitic and silica-undersaturated rock type might be expected to be more serious than for more basic and ultrabasic rock types. Other properties of the major element matrices that might affect analyte signal suppression are the major element atomic masses and element-oxygen bond dissociation energies. Mean data for these are also given above and show that only G-2 and STM-1 have values differing from the other rocks types and the overall mean molecular properties for the major elements seem to be fairly similar.

\subsection{Calibrating Correction Factors for Spectral Interferences from Doubly-Charged $\left(\mathrm{X}^{2+}\right)$ Ions and $\mathrm{X}^{+-} 0$ and $\mathrm{X}^{+-} \mathrm{OH}$ Polyatomic Complexes}

The analytical data obtained in 2017 were calibrated using the data given at the top of Table 3 (as \% count rate ratios for $\mathrm{X}^{2+} / \mathrm{X}^{+}$) while corrections from September 2018 are shown lower down in Table 3. It is clear that the proportions of doubly charged $\mathrm{Ba}$ and $\mathrm{Ce}$ are different for the 2017 and 2018 experiments; this reflects significantly different plasma properties and points to the need to carry out such calibrations with every batch of analyses which requires such data to obtain robust concentration data.

Longerich et al. (1987) showed that the percentage $\mathrm{XO} / \mathrm{X}$ ratios for $\mathrm{Ba}$ and the REE suite with ratios decrease irregularly from $\sim 51 \%$ for La and Ce to $\sim 2 \%$ for $\mathrm{Lu}$ but with $\mathrm{Eu}$ and $\mathrm{Yb}$ showing distinctly lower ratios of 0.3 and $0.09 \%$, respectively; the $\mathrm{BaO} / \mathrm{Ba}$ ratio was $\sim 1.2 \%$. They found that the oxide ratio was closely related to the $\mathrm{X}-\mathrm{O}$ bond strength (in $\mathrm{kcal} / \mathrm{mole}$ ); using their data we obtain a linear least squares fit of

$$
\left(\frac{\mathrm{XO}}{\mathrm{X}}\right) \%=\exp \left(0.050(\mathrm{X}-\mathrm{O})_{\text {bond-strength }}-6.241\right) \quad\left(\mathrm{R}^{2} 0.943\right)
$$

LREE oxide ratios reported by Shibata et al. (1991) obtained by ICP-MS using a nebulizer source showed similar values but were slightly lower for REE with lower bond strengths. Dulski (1994) also studied polyatomic complexing for Ba and the REE suite and provided data for both $\mathrm{XO} / \mathrm{X}$ and $\mathrm{XOH} / \mathrm{X}$ proportions (as \%) and commented that the shape of the trend vs REE species was similar to that reported by Longerich et al. (1990); however, the oxide abundances were about an order of magnitude lower (i.e., $\mathrm{La}, \mathrm{Ce} \sim 3 \%, \mathrm{Lu} \sim 0.4 \%, \mathrm{Eu} \sim 0.7 \%, \mathrm{Yb}$ $\sim 0.2$ ). The hydroxide abundances were, in turn, about an order of magnitude smaller than those for the oxides except that Dulski (1994) found that $\mathrm{BaO}$ and 
Table 3. Calibration of spectral interferences (as \% ratios of count rates) from doubly charged, oxide, and hydroxide components on target analytes, mainly for REE. Calibrations for 2017 and 2018 are shown separately.

\begin{tabular}{|c|c|c|c|c|c|c|c|c|}
\hline $\begin{array}{l}\text { Mass number } \\
\text { of element X }\end{array}$ & $\begin{array}{l}\text { Interfering } \\
\text { Species, } \mathrm{X}\end{array}$ & $\begin{array}{c}\mathrm{X} \text { ratio } \\
\%\end{array}$ & $\begin{array}{c}\mathrm{XO} / \mathrm{X} \\
\%\end{array}$ & Analyte & $\begin{array}{c}\mathrm{XOH} / \mathrm{X} \\
\%\end{array}$ & Analyte & $\begin{array}{c}\mathrm{XO}+\mathrm{XOH} \\
\%\end{array}$ & Analyte \\
\hline \multicolumn{9}{|l|}{ November 2017} \\
\hline \multicolumn{9}{|l|}{$2+$ content } \\
\hline 90 & $\mathrm{Zr}^{2+} / \mathrm{Zr}^{+}$ & 0.090 & & & & & & ${ }^{45} \mathrm{Sc}$ \\
\hline 138 & $\mathrm{Ba}^{2+} / \mathrm{Ba}^{+}$ & 2.27 & & & & & & ${ }^{69} \mathrm{Ga}$ \\
\hline 140 & $\mathrm{Ce}^{2+} / \mathrm{Ce}^{+}$ & 1.35 & & & & & & ${ }^{70} \mathrm{Ge}$ \\
\hline \multicolumn{9}{|l|}{ O content } \\
\hline $138 / 154$ & ${ }^{138} \mathrm{Ba}^{16} \mathrm{O}^{1} \mathrm{H}+{ }^{137} \mathrm{BaOH}$ & & & & & & 0.105 & ${ }^{154} \mathrm{Sm}, \mathrm{Gd}$ \\
\hline $140 / 156$ & ${ }^{140} \mathrm{Ce}^{16} \mathrm{O}$ & & 1.32 & & & & & ${ }^{156} \mathrm{Gd}$ \\
\hline $141 / 157$ & ${ }^{141} \operatorname{Pr}^{16} \mathrm{O}$ & & 0.585 & & & & & ${ }^{157} \mathrm{Gd}$ \\
\hline \multicolumn{9}{|l|}{ September 2018} \\
\hline \multicolumn{9}{|l|}{$2+$ content } \\
\hline 138 & $\mathrm{Ba}^{2+} / \mathrm{Ba}^{+}$ & $4.28(2)$ & & & & & & ${ }^{69} \mathrm{Ga}$ \\
\hline 138 & $\mathrm{Ce}^{2+} / \mathrm{Ce}^{+}$ & $1.0(1)$ & & & & & & ${ }^{69} \mathrm{Ga}$ \\
\hline 142 & $\mathrm{Ce}^{2+} / \mathrm{Ce}^{+}$ & $0.91(1)$ & & & & & & ${ }^{71} \mathrm{Ga}$ \\
\hline 142 & $\mathrm{Nd}^{2+} / \mathrm{Nd}^{+}$ & 0.62 & & & & & & ${ }^{71} \mathrm{Ga}$ \\
\hline 144 & $\mathrm{Nd}^{2+} / \mathrm{Nd}^{+}$ & 0.58 & & & & & & ${ }^{72} \mathrm{Ge}$ \\
\hline 148 & $\mathrm{Nd}^{2+} / \mathrm{Nd}^{+}$ & 0.66 & & & & & & ${ }^{74} \mathrm{Ge}$ \\
\hline \multicolumn{9}{|l|}{$\mathrm{O}, \mathrm{OH}$ content } \\
\hline $133 / 149$ & ${ }^{133} \mathrm{Cs},{ }^{16} \mathrm{O}$ & & 0.0005 & n.s. & & & & \\
\hline $135 / 151$ & ${ }^{135} \mathrm{Ba}^{16} \mathrm{O}+{ }^{134} \mathrm{BaO}^{1} \mathrm{H}$ & & & & & & 0.053 & ${ }^{151} \mathrm{Eu}$ \\
\hline $136 / 152$ & ${ }^{136} \mathrm{Ba}^{16} \mathrm{O}+{ }^{135} \mathrm{BaOH}$ & & 0.04 & & 0.07 & & 0.09 & ${ }^{152} \mathrm{Sm}, \mathrm{Gd}$ \\
\hline $137 / 153$ & ${ }^{137} \mathrm{Ba}^{16} \mathrm{O}+{ }^{136} \mathrm{BaOH}$ & & & & & & 0.082 & ${ }^{153} \mathrm{Eu}$ \\
\hline $138 / 154$ & ${ }^{138} \mathrm{Ba}^{16} \mathrm{O}+{ }^{137} \mathrm{BaOH}$ & & 0.028 & ${ }^{155} \mathrm{Gd}$ & & & & \\
\hline $138 / 155$ & ${ }^{138} \mathrm{Ba}^{16} \mathrm{O}^{1} \mathrm{H}$ & & & & 0.08 & ${ }^{155} \mathrm{Gd}$ & & \\
\hline $136 / 152$ & ${ }^{136} \mathrm{Ce}^{16} \mathrm{O}$ & & 0.44 & ${ }^{152} \mathrm{Sm}, \mathrm{Gd}$ & & & & \\
\hline $136 / 153$ & ${ }^{136} \mathrm{Ce}^{16} \mathrm{O}^{1} \mathrm{H}$ & & & & 0.12 & ${ }^{153} \mathrm{Eu}$ & & \\
\hline $138 / 154$ & ${ }^{138} \mathrm{Ce},{ }^{16} \mathrm{O}$ & & 0.45 & ${ }^{154} \mathrm{Sm}, \mathrm{Gd}$ & & & & \\
\hline $138 / 155$ & ${ }^{138} \mathrm{Ce}^{16} \mathrm{O}^{1} \mathrm{H}$ & & & & 0.096 & ${ }^{155} \mathrm{Gd}$ & & \\
\hline $140 / 156$ & ${ }^{140} \mathrm{Ce}^{16} \mathrm{O}$ & & 0.47 & ${ }^{156} \mathrm{Gd}, \mathrm{Dy}$ & & & & \\
\hline $140 / 157$ & ${ }^{140} \mathrm{Ce}^{16} \mathrm{O}^{1} \mathrm{H}$ & & & & 0.084 & ${ }^{157} \mathrm{Gd}$ & & \\
\hline $142 / 158$ & ${ }^{142} \mathrm{Ce}^{16} \mathrm{O}$ & & 0.48 & ${ }^{158} \mathrm{Gd}, \mathrm{Dy}$ & & & & \\
\hline $142 / 159$ & ${ }^{142} \mathrm{Ce}^{16} \mathrm{O}^{1} \mathrm{H}$ & & & & 0.098 & ${ }^{159} \mathrm{~Tb}$ & & \\
\hline $141 / 157$ & ${ }^{141} \operatorname{Pr}^{16} \mathrm{O}$ & & 0.54 & ${ }^{167} \mathrm{Gd}$ & & & & \\
\hline $141 / 158$ & ${ }^{141} \operatorname{Pr}^{16} \mathrm{O}^{1} \mathrm{H}$ & & & & 0.070 & ${ }^{158} \mathrm{Gd}, \mathrm{Dy}$ & & \\
\hline
\end{tabular}




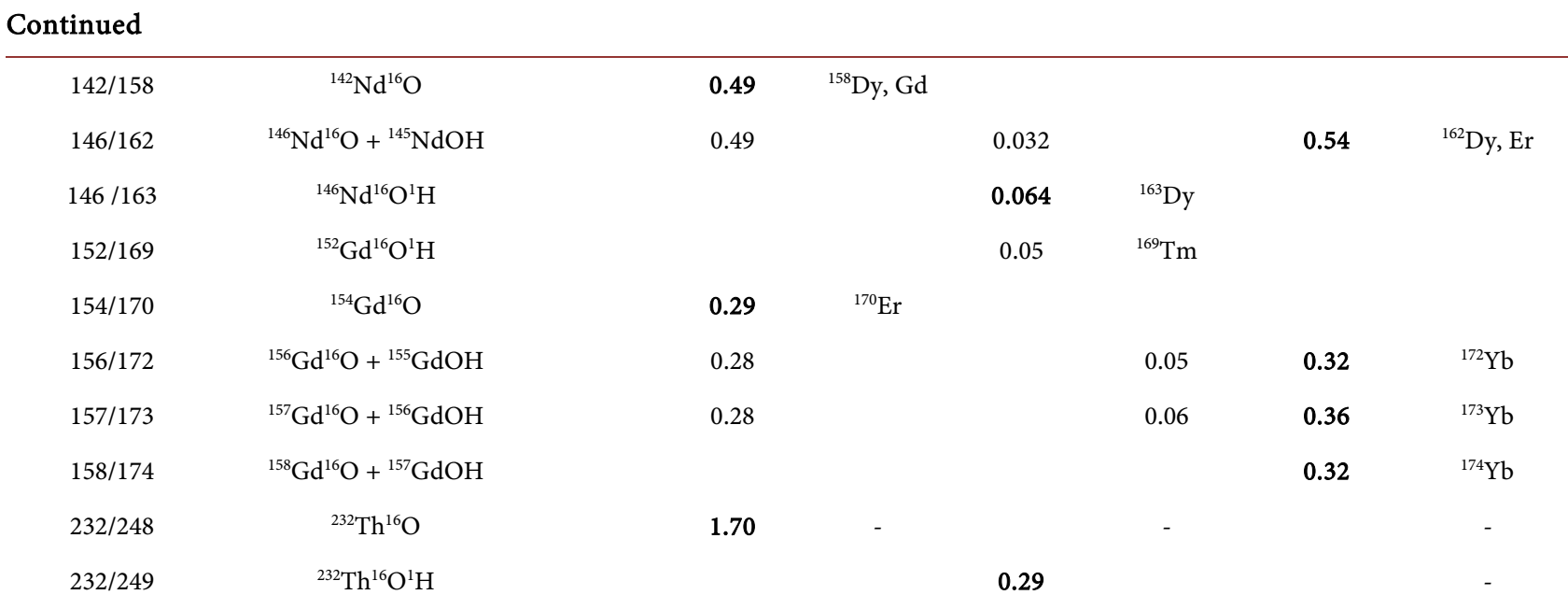

$\mathrm{BaOH}$ ratios were very similar at 0.12 and 0.13 , respectively. Our linear least squares fits for those data give:

$$
\left(\frac{\mathrm{XO}}{\mathrm{X}}\right) \%=\exp \left(0.052(\mathrm{X}-\mathrm{O})_{\text {bond-strength }}-8.6758\right) \quad\left(\mathrm{R}^{2} 0.9258\right)
$$

and

$$
\left(\frac{\mathrm{XOH}}{\mathrm{X}}\right) \%=\exp \left(0.0523(\mathrm{X}-\mathrm{O})_{\text {bond-strength }}-11.234\right)\left(\mathrm{R}^{2} 0.9043\right)
$$

These slopes are effectively the same for both $\mathrm{XO} / \mathrm{X}$ and $\mathrm{XOH} / \mathrm{X}$ and are only slightly larger than that for the Longerich et al. data (i.e., 0.050, see above).

These data provide a key understanding of the potential interferences for $\mathrm{Ba}$ and the REE suite for both oxide and hydroxides, in particular demonstrating how ICP-MS techniques have developed to reduce the scale of such interferences. Robinson et al. (2006) also provided important data on Ba and REE oxide and hydroxide interferences in their table 2 and table 3 . However, it seems to us that oxide or hydroxide interferences for Ba on LREE and for lighter REE on those REE isotopes with mass numbers heavier by $16\left({ }^{16} \mathrm{O}\right)$ or $17\left({ }^{16} \mathrm{O}+{ }^{1} \mathrm{H}\right)$ require more careful assessment especially in our work as we will also be dealing with analyses of some Ba- and REE-rich rock types during our ongoing research on alkaline rocks.

Thus, based on the information in Robinson et al. (2006) we initially determined XO/X percentages for ${ }^{138} \mathrm{Ba},{ }^{138} \mathrm{Ce}$ and ${ }^{141} \mathrm{Pr}$; data are given for 2017 experiments towards the top of Table 3. In September 2018 we subsequently (experiment 6918) carried out a wider ranging study of oxide and hydroxide species for several isotopic complexes of $\mathrm{Ba}, \mathrm{Ce}, \mathrm{Pr}, \mathrm{Nd}$, and $\mathrm{Gd}$. We also studied data for $\mathrm{Cs}$ and $\mathrm{Th}$ standards to extend the range of $\mathrm{X}$-O bond strengths for assessing the relationship between oxide proportion in the plasma and the intrinsic stability of the species; data obtained are given in the lower part of Table 3. It is clear, for isotopes of a given element which only differ by one mass number, that the oxide for the heavier isotope (e.g. ${ }^{136} \mathrm{Ba}^{16} \mathrm{O}$ ) is interfered with by the hydroxide 
for the lower mass $\left({ }^{135} \mathrm{Ba}^{16} \mathrm{O}^{1} \mathrm{H}\right.$ ) (see Table 3); this makes it more difficult to extract unique data for both species. For adjacent mass numbers it is possible to calculate independent values using simultaneous equations and where data for either oxide or hydroxide proportions are available the other can be calculated; in both of these cases the isotopic relative abundances must be incorporated. The situation is much simpler where isotopes differ by two mass numbers as shown by the Ce data in Table 3. Of course, it is not always essential to have unique values for oxide and hydroxide proportions as corrections to a given analyte mass number would need to be made for the actual combination of oxide and hydroxide interfering components at that mass number. For example, we use the combined count rate at mass number 153 (i.e., ${ }^{137} \mathrm{BaO}+{ }^{136} \mathrm{BaOH}$ ) to correct the count rate at mass number 153 to determine the bulk Eu concentration from the ${ }^{153} \mathrm{Eu}$ isotope. Indeed, this is the way we correct for most of the oxide/hydroxide interferences on the REE isotopes chosen for the analyses and the data used for each analyte element mass number are shown in the last column of Table 3.

Figure 1 shows the Dulski (1994) data together with our data for the variation of $\ln (\mathrm{XO} / \mathrm{X})$ and $\ln (\mathrm{XOH} / \mathrm{X})$ (as \%) vs $\mathrm{X}-\mathrm{O}$ bond-strength; our oxide trend gives a linear least squares fit of:

$$
\left(\frac{\mathrm{XO}}{\mathrm{X}}\right) \%=\exp \left(0.0597(\mathrm{X}-\mathrm{O})_{\text {bond-strength }}-11.577\right)\left(\mathrm{R}^{2}\right. \text { 0.9741) }
$$

which has a slightly steeper trend compared with Dulski's values but our trend is weighted by the point for Cs which has a substantial uncertainty because of its very low $\mathrm{XO}$ concentration. The data that we have for $\mathrm{XOH} / \mathrm{X}$ fall on a similar trend to that for the Dulski XOH/X data (Figure 1). Thus the trends for Dulski's

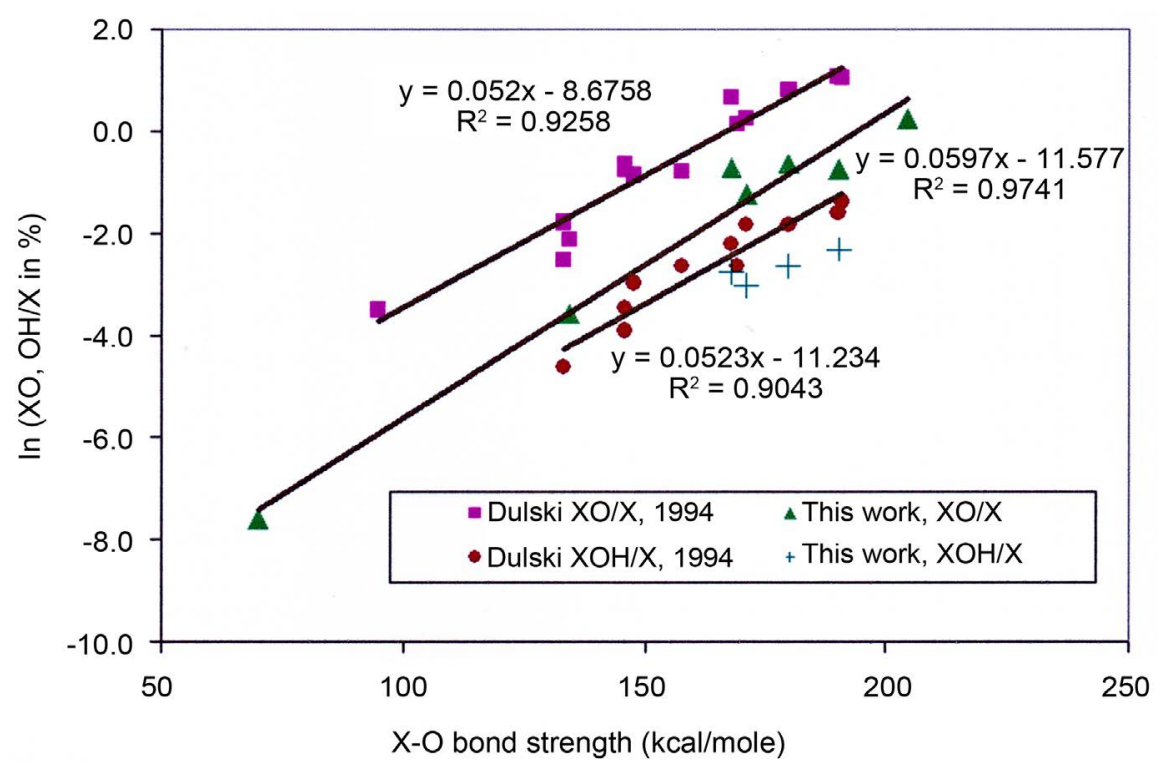

Figure 1. Dependence of the proportions of REE oxide and hydroxide count rates compared to those for the relevant isotope cps as a function of REE oxide bond strength (units, $\mathrm{kcal} / \mathrm{mole}$ ). Data points and linear regression equations, where appropriate, are shown for the data from Dulski (1994) and our work (Table 3); see text for further explanation. 
and our data for both $\mathrm{XO}$ and $\mathrm{XOH}$ vs $\mathrm{X}-\mathrm{O}$ bond-strengths have essentially the same slope and simply point to decreasing concentrations of the polyatomic complexes in the order Dulski XO/X, our XO/X, Dulski XOH/X, our XOH/X; the oxide and hydroxide values mentioned by Robinson et al. (2006) and Ardini et al. (2010) show similar relationships. Of course, such well-defined trends can be used to predict oxide or hydroxide proportions for REE elements not the subject of more detailed study; for example using our fits shown in Figure 1 (Equation (4) above) we can predict that the proportions of XO/X for La, Sm, Dy and $\mathrm{Yb}$ would be $0.83 \%, 0.06 \%, 0.05 \%$ and $0.003 \%$, respectively. It is clear that the levels of oxides and hydroxides encountered, at different times in different laboratories, depend on the plasma characteristics. However, the fact that the REE suite tends to show the same dependence on the primary property of X-O bond-strength suggests that, as long as one REE element calibration is run with each set of samples, it would be possible to predict the oxide and hydroxide proportion for ALL of the other REE by assuming the same slope defined here. We use Ce for our plasma optimization and suggest that it is the most appropriate calibrant but stress that it would be advantageous to monitor the $\mathrm{XOH} / \mathrm{X}$ ratio as well as that for $\mathrm{XO} / \mathrm{X}$ which is routinely monitored with the Agilent plasma tuning protocol.

Based on the measured calibration data for $\mathrm{CeO} / \mathrm{Ce}$ and $\mathrm{CeOH} / \mathrm{Ce}$ it would also be possible to assess our measured data for $\mathrm{CeOH}$ by modifying the linear least squares fit for the oxide data by keeping the same coefficient but increasing the constant by the difference between the natural logarithms for the $\mathrm{CeO} / \mathrm{Ce}$ and $\mathrm{CeOH} / \mathrm{Ce}$ concentration ratios. For our data this would involve modifying Equation (4) to give:

$$
\left(\frac{\mathrm{XOH}}{\mathrm{X}}\right) \%=\exp \left(0.05297(\mathrm{X}-\mathrm{O})_{\text {bond-strength }}-(11.577+2.069)\right)
$$

For our experiment set 6918, this equation gives predicted values for $\mathrm{La}, \mathrm{Sm}$, Dy and $\mathrm{Yb}$ of $0.11,0.008,0.007$ and 0.0003 , respectively, all of which are smaller than the XOH/X values reported by Dulski (1994).

The utility of this approach can be illustrated by using the least squares fit equation for Dulski's XO/X vs X-O bond-strength data (Equation (2)) modified by adding the difference between the natural logarithms of the $\mathrm{CeO} / \mathrm{Ce}$ and $\mathrm{CeOH} / \mathrm{Ce}$ ratios as follows to calculate Dulski-(XOH/X) values as follows:

$$
\left(\frac{\mathrm{XOH}}{\mathrm{X}}\right) \%=\exp \left(0.052(\mathrm{X}-\mathrm{O})_{\text {bond-strength }}-(8.6758+2.558)\right)
$$

Except for $\mathrm{Ba}$, this calculation gives very good agreement between his measured and our calculated $\mathrm{XOH} / \mathrm{X}$ ratios.

Finally we have used our measured $(\mathrm{XO}+\mathrm{XOH}) / \mathrm{X}$ shown in Table 3 to assess the dependence on $\mathrm{X}-\mathrm{O}$ bond-strength as follows:

$$
\left(\frac{\mathrm{XO}+\mathrm{XOH}}{\mathrm{X}}\right) \%=\exp \left(0.04(\mathrm{X}-\mathrm{O})_{\text {bond-strength }}-7.971\right)
$$


This equation could be used to approximate the correction interference possible on a given analyte isotope as long as the relative abundances for the adjacent mass number isotopes of the target element responsible for the oxide/hydroxide interference are not too dissimilar.

In the following sections we will use this general approach together with our measured $(\mathrm{XO}+\mathrm{XOH}) / \mathrm{X}$ ratios for the relevant interfering mass numbers (Table 3) to correct the concentrations for the REE analyte isotopes that we use for the analyses obtained for our 2018 data (experiment 6918). In addition, to make similar corrections for our larger database obtained in our 2017 work (experiments 6717 and 5917) we have used our new equations for the Dulski (1994) data together with our $\mathrm{CeO} / \mathrm{Ce}$ calibrations from 2017 to obtain $\mathrm{XO} / \mathrm{X}$ and $\mathrm{XOH} / \mathrm{X}$ values to assess the corrections required for the full REE suite in the 2017 dataset as follows:

$$
\left(\frac{\mathrm{XO}}{\mathrm{X}}\right) \%=\exp \left(0.052(\mathrm{X}-\mathrm{O})_{\text {bond-strength }}-9.5804\right)
$$

and

$$
\left(\frac{\mathrm{XOH}}{\mathrm{X}}\right) \%=\exp \left(0.052(\mathrm{X}-\mathrm{O})_{\text {bond-strength }}-12.14\right)
$$

Using this approach we have assessed the possible peak interferences for the full REE suite and we have found that such interferences are only crucial for a restricted number of target elements (cf Robinson et al., 2006). Thus essential corrections for the 2017 data are those for: ${ }^{137} \mathrm{Ba}^{16} \mathrm{O}+{ }^{136} \mathrm{Ba}^{16} \mathrm{O}^{1} \mathrm{H}$ (correction factor ${ }^{137} \mathrm{Ba}$ cps $\times 0.0008$ (Table 3) on ${ }^{153} \mathrm{Eu}$ cps (e.g., $~ 5 \%$ for BCR-1); ${ }^{141} \operatorname{Pr}^{16} \mathrm{O}$ $\left({ }^{141} \mathrm{Pr} \mathrm{cps} \times 0.01\right)$ and ${ }^{140} \mathrm{Ce}^{16} \mathrm{O}^{1} \mathrm{H}\left({ }^{140} \mathrm{Ce} \mathrm{cps} \times 0.00104\right)$ on ${ }^{157} \mathrm{Gd}$ cps $(\sim 8 \%$ for BCR-1). Less significant are those for: ${ }^{156} \mathrm{Gd}^{16} \mathrm{O}\left({ }^{156} \mathrm{Gd} \mathrm{cps} \times 0.005\right)$ on ${ }^{172} \mathrm{Yb} \mathrm{cps}$ ( 1.3\% for BCR-1); ${ }^{159} \mathrm{~Tb}^{16} \mathrm{O}\left({ }^{159} \mathrm{~Tb}\right.$ cps $\left.\times 0.0013\right)$ on ${ }^{175} \mathrm{Lu}$ cps $(\sim 1 \%$ for BCR-1). We also have used our deduced corrections for ${ }^{143} \mathrm{NdO}$ and ${ }^{142} \mathrm{CeOH}$ and isotope relative abundances to assign the corrections for ${ }^{146} \mathrm{Nd}$ cps $\times 0.0014 \times$ $(0.122 / 0.172)$ and ${ }^{140} \mathrm{Ce}$ cps $\times 0.00010 \times(0.111 / 0.885)$ on ${ }^{159} \mathrm{~Tb}$ cps $(\sim 2 \%$ for BCR-1). Corrections for the other REE isotopes used were much smaller $\ll$ $0.3 \%$ (e.g. ${ }^{163} \mathrm{Dy},{ }^{166} \mathrm{Er}$ ). We will examine further possible interferences for some REE-rich syenitic rocks in Section 4.6.3.

\subsection{Analyses of DF500 Solutions without Internal Standard Correction}

Our results will be reported firstly for our chosen main standard basalt rock BCR-1. Average values for the full element set ( $\mathrm{Li}$ to $\mathrm{U}$ ) for solutions with $\mathrm{DF}=$ 500 , are based on comparing peak intensities with those for our external multi-element standard solutions as detailed above.

\subsubsection{BCR-1}

The average analyses for BCR-1 are uniformly lower than the recommended values and this is shown by the data in Table 4 with concentration ratios referred 
Table 4. Average analyses for all elements in international reference rocks divided by adopted values (Element Recovery Ratios, ERR). The two columns at the RHS show averages and standard deviations for each element in all four rocks and values at bottom show averages for all elements in each rock for $\mathrm{Li}$ to $\mathrm{U}$ and $\mathrm{Rb}$ to $\mathrm{U}$.

\begin{tabular}{|c|c|c|c|c|c|c|}
\hline & BCR-1 & BHVO-1 & AGV-1 & G-2 & Average & Std. dev. \\
\hline & DF500 & DF500 & DF500 & DF500 & all stds & all stds \\
\hline & No IS & No IS & No IS & No IS & & \\
\hline & Ratio & Ratio & Ratio & G2 & & \\
\hline $\mathrm{Li}$ & 0.82 & 0.81 & 0.84 & 0.87 & 0.84 & 0.03 \\
\hline $\mathrm{Be}$ & 0.77 & 0.92 & 0.95 & 0.98 & 0.91 & 0.09 \\
\hline B & 0.63 & 0.48 & 0.98 & 0.58 & 0.67 & 0.22 \\
\hline $\mathrm{Sc}$ & 0.85 & 0.89 & 0.98 & 0.84 & 0.87 & 0.08 \\
\hline $\mathrm{V}$ & 0.97 & 0.92 & 0.92 & 1.04 & 0.96 & 0.06 \\
\hline $\mathrm{Cr}$ & 0.83 & 0.84 & 0.81 & 0.82 & 0.83 & 0.01 \\
\hline $\mathrm{Co}$ & 0.83 & 0.79 & 0.81 & 0.92 & 0.84 & 0.06 \\
\hline $\mathrm{Ni}$ & 0.83 & 0.79 & 0.82 & 0.68 & 0.78 & 0.07 \\
\hline $\mathrm{Cu}$ & 0.79 & 0.74 & 0.77 & 0.78 & 0.77 & 0.02 \\
\hline $\mathrm{Zn}$ & 0.84 & 0.80 & 0.82 & 0.93 & 0.85 & 0.06 \\
\hline $\mathrm{Rb}$ & 0.99 & 0.96 & 0.95 & 0.94 & 0.96 & 0.02 \\
\hline $\mathrm{Sr}$ & 0.90 & 0.87 & 0.86 & 0.87 & 0.88 & 0.02 \\
\hline $\mathrm{Y}$ & 0.89 & 0.87 & 0.87 & 0.89 & 0.88 & 0.07 \\
\hline $\mathrm{Zr}$ & 0.95 & 0.96 & 1.02 & 0.65 & 0.89 & 0.16 \\
\hline $\mathrm{Nb}$ & 0.95 & 0.95 & 0.94 & 1.02 & 0.96 & 0.04 \\
\hline Cs & 0.94 & 0.86 & 0.92 & 0.95 & 0.92 & 0.03 \\
\hline $\mathrm{Ba}$ & 0.90 & 0.84 & 0.86 & 0.89 & 0.87 & 0.03 \\
\hline $\mathrm{La}$ & 0.92 & 0.92 & 0.93 & 0.87 & 0.92 & 0.02 \\
\hline $\mathrm{Ce}$ & 0.91 & 0.90 & 0.93 & 0.93 & 0.92 & 0.02 \\
\hline Pr & 0.94 & 0.91 & 0.96 & 0.89 & 0.93 & 0.03 \\
\hline $\mathrm{Nd}$ & 0.89 & 0.89 & 0.91 & 0.89 & 0.89 & 0.09 \\
\hline $\mathrm{Sm}$ & 0.96 & 0.96 & 0.97 & 0.95 & 0.96 & 0.09 \\
\hline $\mathrm{Eu}$ & 0.97 & 0.99 & 0.96 & 0.84 & 0.96 & 0.02 \\
\hline $\mathrm{Gd}$ & 0.89 & 0.88 & 0.88 & 0.95 & 0.90 & 0.03 \\
\hline $\mathrm{Tb}$ & 0.88 & 0.92 & 0.88 & 0.94 & 0.89 & 0.02 \\
\hline Dy & 0.86 & 0.88 & 0.87 & 0.83 & 0.86 & 0.02 \\
\hline Ho & 0.90 & 0.90 & 0.89 & 0.87 & 0.89 & 0.02 \\
\hline $\mathrm{Er}$ & 0.91 & 0.96 & 0.95 & 0.94 & 0.94 & 0.03 \\
\hline $\mathrm{Tm}$ & 0.79 & 0.85 & 0.78 & 0.77 & 0.80 & 0.04 \\
\hline $\mathrm{Yb}$ & 0.87 & 0.92 & 0.90 & 0.88 & 0.89 & 0.02 \\
\hline $\mathrm{Lu}$ & 0.90 & 0.94 & 0.91 & 0.89 & 0.91 & 0.03 \\
\hline
\end{tabular}




\begin{tabular}{|c|c|c|c|c|c|c|}
\hline Continued & & & & & & \\
\hline $\mathrm{Hf}$ & 0.94 & 0.94 & 0.95 & 0.61 & 0.86 & 0.17 \\
\hline $\mathrm{Ta}$ & 0.88 & 0.91 & 0.93 & 0.86 & 0.90 & 0.03 \\
\hline $\mathrm{Pb}$ & 0.77 & 1.16 & 0.89 & 0.85 & 0.92 & 0.16 \\
\hline Th & 0.97 & 0.99 & 1.00 & 0.97 & 0.98 & 0.01 \\
\hline $\mathrm{U}$ & 0.82 & 0.87 & 0.83 & 0.82 & 0.84 & 0.02 \\
\hline & Av. Rati & & & & & \\
\hline Av. Li-U & 0.88 & 0.89 & 0.90 & 0.87 & & \\
\hline Stdev. Li-U & 0.07 & 0.10 & 0.06 & 0.10 & & \\
\hline Av. Rb-U & 0.90 & 0.92 & 0.91 & 0.88 & & \\
\hline Stdev. Rb-U & 0.05 & 0.06 & 0.05 & 0.09 & & \\
\hline
\end{tabular}

to as "element recovery ratios" (ERR); the data are shown for the whole element suite studied in Figure 2(A). All of the ERR values for BCR-1 fall within a narrow range from 0.77 to 0.97 except the value for $\mathrm{B}$ at 0.63 . Makishima et al. (1997) and Makishima et al. (2009) have predicted that very low yields of B (9\% to $84 \%$, depending on the sample matrix) would result from the loss of volatile $\mathrm{BF}_{3}$ during the sample digestion and they advocate the use of mannitol during the sample dissolution (see later). The lower recovery for the other elements in our analyses needs to be assessed related to the chemical affinities of different groups of elements. Thus, Makishima et al. (2009) classified elements into 7 groups, two of which depend on their behaviours in the presence of fluorine, namely: "fluorophile elements" (Ti, Zr, Hf, Nb, Ta; all form soluble fluorides liable to precipitate when hydrolysed); and "insoluble fluoride-forming elements" (B, Be, Mg, Ca, Sr, Cr, Ni, REE, Th, which might precipitate during digestion). Makishima et al. $(2006,2009)$ advocated the use of separate rock digests for analysing these two groups of elements and, in addition, stress that "REE data obtained without $\mathrm{HClO}_{4}$ should be doubted" (Makishima et al., 2009). Tanaka et al. (2003) and Yokoyama et al. (1999) paid special attention to analysing a suite of elements including REE and HFSE elements and found that the presence of fine-grained $\mathrm{Ca}, \mathrm{Mg}$, Al-containing precipitates, which could be centrifuged from the supernatant solution, resulted in the latter being depleted in some trace elements, particularly the REE. Makishima et al. (2009) describe such solutions as having a "clear" appearance; note that light scattering experiments of clear colloidal "solutions" generally indicate a particle size for the precipitate of $<500$ $\mathrm{nm}$. The bulk composition of BCR-1 places it within the Makishima-Al-Mg-Ca compositional field defining poor recovery of $\mathrm{Zr}$ and $\mathrm{Hf}$ due to their incorporation in insoluble, perhaps colloidal, fluorides. We have assessed this in our 2018 experiments by analysing 10 identical samples of a BCR-1 solution (experiment 6918). For these analyses, 10 sweeps through the full mass range were carried out using a dwell time of $0.1 \mathrm{~s}$ for each point and each individual count rate was recorded and assessed. If insoluble components smaller than $500 \mathrm{~nm}$ suspended in 

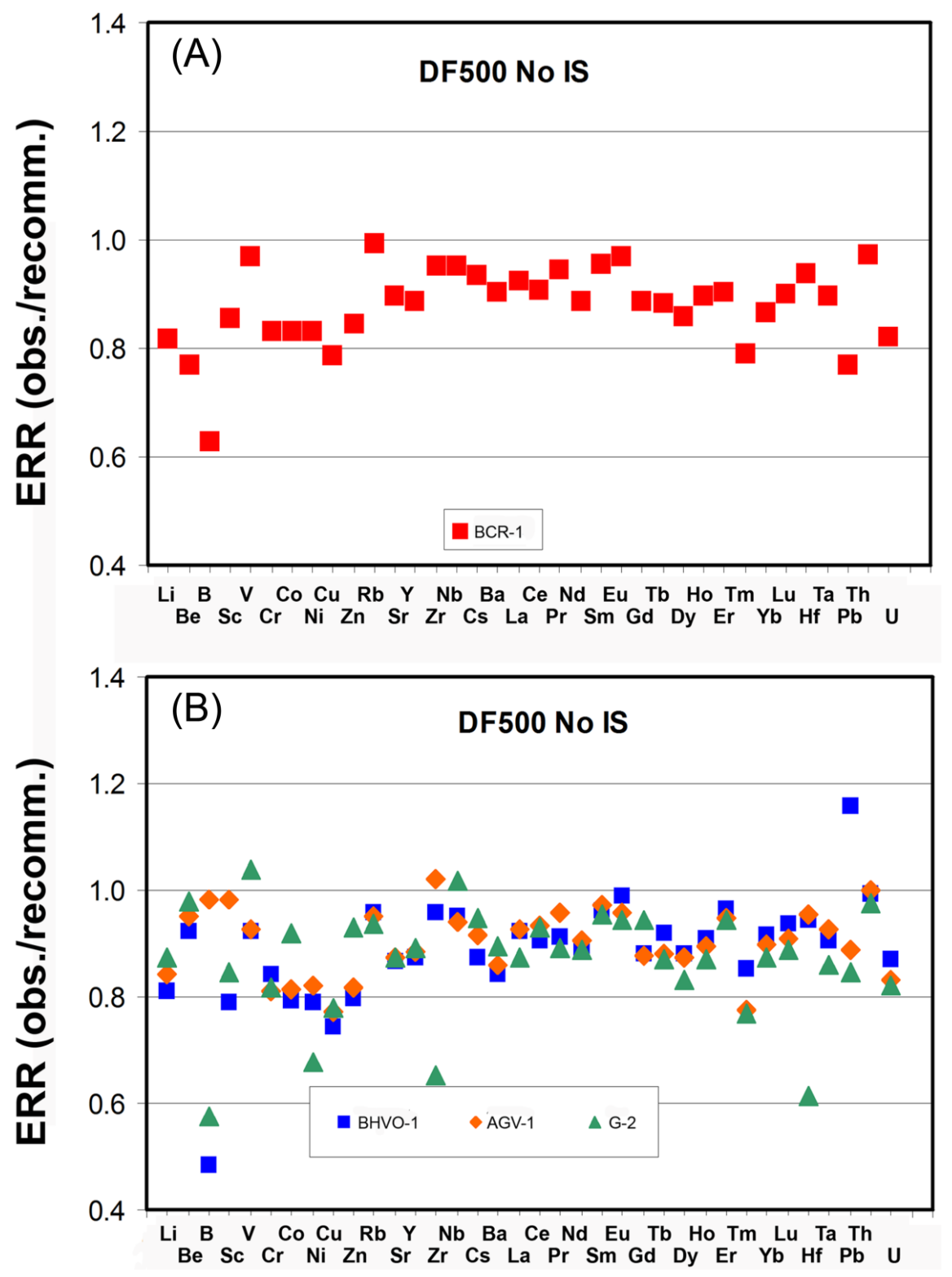

Figure 2. Element Recovery Ratios (ERR) [observed value/recommended value) for reference rock solutions having dilution factors (DF) of 500; no correction is made for an internal standard. Figure 2(A), ERR values shown are for the element suite studied of increasing mass from ${ }^{7} \mathrm{Li}$ to ${ }^{235} \mathrm{U}$ in BCR-1; ERR values cluster around an average value of 0.90 with somewhat higher values at the centre of the mass range. Figure 2(B), ERR values for average analyses for BHVO-1, AGV-1 and G-2 all fall on a similar trend (convex-up) to that shown for BCR-1 in Figure 2(A) and show similar sinuous fluctuations. Low points for B reflect analytical problems and/or unreliable "adopted" values while low $\mathrm{Zr}$ in G-2 is due to variable dissolution of zircon during sample preparation.

nebulised droplets $\sim 10 \mu \mathrm{m}$ is size were sprayed into the plasma, such an experiment might be expected to encounter spikes in count rates when a single "dense" particle is excited in the plasma rather than the solution it is suspended in but no clear "rogue" counts are detected for Zr or Hf, or for any of the other 34 elements studied here; the average RSD for any of the individual count rates in the 
10 sweeps range from $<0.5 \%$ to $1.5 \%$. The maximum particle size that can be studied by single-particle methods (spICP-MS) has been reported to be $2 \mu \mathrm{m}$ which satisfies the conditions for studying nanoparticles (Pace et al., 2011); note also that a study of slurries using plasma OES methods (3\% w/v suspensions of $<20 \mu \mathrm{m}$ particles) used peak integration times of $0.1 \mathrm{~s}$ (Ślachciński, 2018), the same as our timescale. Thus we detect no evidence for the presence of insoluble fluorides suspended in our "clear" rock digests. If they are present, the tightly constrained count rates show that the overall analysis for each element is an average of the suspended particles and the carrier solutions. Note that Pace et al. (2011) report that analysis of slurries containing $<1 \% \mathrm{w} / \mathrm{v}$ of solid particles would not be expected to affect the nebulization process so the analyte concentrations obtained in our analyses should provide the average composition for the bulk sample even if colloidal particles were to be present.

In any case, assessment of the ERR values for BCR-1 show that the insoluble-fluoride-type elements (some $3 \mathrm{~d}$ elements and all REE elements) mainly range from ERR $=0.83$ to 0.96 and the HFSE elements fall at the upper end of this range (0.95). More significantly, Tanaka's "bare cation, aquaphile" elements ( $\mathrm{Li}, \mathrm{Cu}, \mathrm{Zn}, \mathrm{Rb}, \mathrm{Ba}, \mathrm{Cs}$; all highly soluble) show the same ERR range (0.83 to 0.99 ) as the supposedly insoluble fluoride elements. We conclude that our analyses of BCR-1 prepared in $\mathrm{HF}$ solutions with $\mathrm{HNO}_{3}$, but without the presence of $\mathrm{HClO}_{4}$, do not show significant element separation effects of the type described by the Makishima group. In addition, there is little evidence that major loss of $\mathrm{B}$ due to its volatility has occurred from the sealed vessels used for our sample preparation.

Figure 2(A) shows that the average compositions for BCR-1 mainly fall in a horizontal band between ratios of 0.8 and 1.0; note that the $3 \mathrm{~d}$ elements from $\mathrm{Cr}$ to $\mathrm{Zn}$ are all close to ERR $=0.8$ while those for $\mathrm{Sc}$ and $\mathrm{V}$ are higher. Although the relatively high values for Sc might suggest an under-correction of ${ }^{45} \mathrm{Sc}$ for doubly charged ${ }^{90} \mathrm{Zr}$ it is likely that interference by a small amount of ${ }^{28} \mathrm{Si}^{16} \mathrm{O}^{1} \mathrm{H}$ is responsible as Robinson et al. (2006) showed that quadrupole MS resolution would not resolve this interference. That for ${ }^{51} \mathrm{~V}$ might be related to interference by residual polyatomic ${ }^{35} \mathrm{Cl}^{16} \mathrm{O}$ with $\mathrm{Cl}$ sourced from $\mathrm{HCl}$ in one of the wash solutions or from anthropogenic contamination of the source rock powders and/or sample preparation equipment. The generally low concentrations determined for $3 \mathrm{~d}$ elements suggest that other interferences noted by Townsend are not an obvious problem in our work. The slightly high $\mathrm{Rb}$ content compared to similar mass elements might reflect that its low FIP leads to more efficient ionisation than for elements of higher FIP.

From $\mathrm{Rb}$ with increasing mass, the points seem to define a sinuous trend with lows at $\mathrm{Y}, \mathrm{Ba}, \mathrm{Tm}$, and $\mathrm{U}$ and highs at $\mathrm{Zr}, \mathrm{Eu}$ and $\mathrm{Hf}$; note that this sinuous trend is present for all of the separate samples of BCR-1 analysed so it is not due to random error. $\mathrm{Pb}$ has common contamination issues so we will not discuss this element further in this study. 
Although our values are uniformly lower than the recommended values there is no consistent dependence of the composition levels recovered for analyte mass numbers varying from $\mathrm{Li}$ to $\mathrm{U}$; this relationship matches that reported by Olesik and Jiao (2017) and contrasts with the findings of Tan and Horlick (1987) that light analyte elements suffer greater count suppression. The average element ratio from $\mathrm{Li}$ to $\mathrm{U}$ is $0.88 \pm 0.07$ while that from $\mathrm{Rb}$ to $\mathrm{U}$ is slightly higher at $0.90 \pm$ 0.06 . We conclude that the average peak suppression (matrix effect) is close to $10 \%$ and that our analytical results do not demonstrate a mass dependence for this sample at least. The count rate suppression of $\sim 10 \%$ is similar to that reported as occurring for basalt rock digests of DF $=1000$ (Yokoyama et al., 2016). Finally, based on the data shown here in Table 2 the variable data reported for $\mathrm{B}$ are mainly expected to reflect the larger blank error possible for this element.

We had hoped to obtain useful quantitative concentrations for BCR-1 in our 2018 experiments (run 6918) but the repeat analyses had generally higher concentrations for all elements with ERR values ranging between average values of 1.1 ( $\mathrm{Li}$ to $\mathrm{Nb}$ ) and 1.0 ( $\mathrm{Ba}$ to $\mathrm{U}$ ). We consider that these higher recoveries could represent the effects of evaporation from the sample tubes so that these data are clearly less reliable than for our 2017 analyses.

\subsubsection{BHV0-1, AGV-1 and G-2}

Our average analyses of international reference materials BHVO-1 (basalt), AGV-1 (andesite) and G-2 (granite) are uniformly lower than the recommended values for each rock. In addition, errors for $\mathrm{B}$ and $\mathrm{Pb}$ are both very high reflecting the low count rates for the former and the commonly encountered contamination problems for both elements. Table 4 shows the averages for ERR values for all the elements in these reference rocks and the data are shown here in Figure 2(B). These "overall averages" are remarkably similar for each rock despite the different major element matrices. Indeed, when the ERR values for each reference rock are compared for the different Tanaka-element-types we find exactly the same relationships to those described for BCR-1 and we conclude that our sample preparation methods using $\mathrm{HF} / \mathrm{HNO}_{3}$ have produced homogeneous, clear solutions without any segregation of different element types. Of course, colloidal particles $(<500 \mathrm{~nm})$ might be present in some of our "clear" solutions (see earlier) but the consistency of the signal count rates suggest that no significant separation has occurred prior to the formation of the ion beam.

Thus, our results for the DF500 solutions (without internal standardization) for BHVO-1, AGV-1, and G-2 show very similar sinuous trends (Figure 2(B)) to that of BCR-1 with highs and lows at similar positions in the sequence. Also shown in Table 4 (in the left hand columns) are separate ERR averages for each element in each of the four standard rocks; comparison of these single element averages shows distinct differences within the element suite. Such differences could indicate different element-specific matrix effects (spectroscopic and/or non-spectroscopic) but could also reflect systematic errors such as incomplete solution of refractory accessory minerals (e.g. zircon or spinel phases) or unreli- 
able chemical standards for some elements. The latter effect would be present in all the samples studied but the former should vary with rock type reflecting the different refractory mineral types occurring in the different rocks.

In Figure 2(B) some of the data points for G-2 plot lower than the other rocks in this figure which might reflect a slightly larger suppression of analyte signal for this rock because of its higher mean FIP value (see earlier, Section 4.2). Overall, despite the different major element compositions between the different rocks the results show essentially the same features as those for BCR-1. The average ratios for the full sample set from Li to $\mathrm{U}$ are BHVO-1 $0.89 \pm 0.10$, AGV-1 $0.90 \pm 0.06, \mathrm{G}-20.87 \pm 0.10$; and from $\mathrm{Rb}$ to $\mathrm{U}$ are $0.92 \pm 0.06,0.91 \pm 0.05,0.88 \pm$ 0.09 , respectively. Note that the trends for all standard rocks are slightly better defined for the $\mathrm{Rb}$ to U. However, Figure 2(B) shows some clear outlying values and the ERR ratios (Table 4) confirm such relationships. The low values for $\mathrm{Zr}$ and Hf in our G-2 data indicate that our sample solution method does not take all of the zircon grains into solution for this rock although it is possible that this rock powder might not be homogeneous at the $0.1 \mathrm{~g}$ level resulting from zircon grains showing a "nugget" effect (Potts, 1987: Ch. 1, pp. 20-22; Potts et al., 2015; Jochum et al., 2015). Indeed one of the G-2 samples prepared had significantly lower $\mathrm{Zr}$ and $\mathrm{Hf}$ ratios than the other two suggesting different amounts of zircon incorporation. However, while zircon is known to concentrate heavy REE much more efficiently than LREE ( $\mathrm{Lu} / \mathrm{La}$ concentration ratio perhaps as high as 1000 5000 (e.g. Belousova et al., 2002)); our REE analyses for G2 do not show any systematic differences for LREE versus HREE within the ERR element recovery values which suggest that zircon is not the major host for REE in reference rock G-2. It is also possible that the low Zr and Hf contents in G-2 might reflect hydrolysis and precipitation of insoluble oxide complexes but note that other HFSE elements $(\mathrm{Nb}$ and $\mathrm{Ta}$ ) do not show such depletions which perhaps is consistent with the observations of Tanaka et al. (2003). Potts (1987) reports analyses of zircon-bearing rocks using alkali carbonate fusions but this complicates the ICP-MS analyses by increasing the TDS load in solution; we prefer to use existing XRF data to report the $\mathrm{Zr}$ concentrations for these rock types.

The low ratios for B in BCR-1, BHVO-1, and G-2 might be due partly to unreliable adopted values for these standard rocks but note that unreliable blank corrections (Table 2) or minor loss due to B volatility could also be a factor. The ratios for the REE data show that our values for Dy and Tm in all of the standard rocks shown in Figure 2 tend to be low. It also seems likely that our $\mathrm{V}$ and $\mathrm{Zr}$ (except for G-2) values might be anomalously high, while our $U$ values tend to be uniformly low, perhaps reflecting loss of some $\mathrm{U}$ as insoluble fluorides (see Yokoyama et al., 1999). However, the scatter for $\mathrm{Ta}, \mathrm{Pb}$, Th and $\mathrm{U}$ also reflects higher errors for solution blanks for these elements (cf. Table 2). Overall, we conclude that the sinuous trend shown for ERR in all four standard rocks is likely to reflect systematic and reproducible matrix effects and that peak interferences are generally not responsible. There is no obvious dependence on element 
FIP and whether the element falls on a "high" or "low" part of the sinuous trend and we are confident about our standard solutions with the possible exception of those for Tm and Dy. We will return to this matter in Section 4.6.

Thus we have shown in Table 4 that the different reference materials (basalts, andesite and granite) have very similar ERR values for the element suite irrespective of their major element compositions. This contrasts with the finding of Cheatham et al. (1993) who used an early generation ICP-MS instrument and reported that the basic rocks and acid/intermediate rocks showed non-linear working curves and had to be treated as two groups. Thus, for our data for representative trace elements in BCR-1, BHVO-1, AGV-1, and G-2, that cover reasonably wide concentration ranges, we fitted background-corrected counts versus recommended concentrations to check the quality of fits. For representative elements (e.g. $\mathrm{Li}, \mathrm{Sc}, \mathrm{Cr}, \mathrm{Rb}, \mathrm{Nb}, \mathrm{Ba}, \mathrm{La}, \mathrm{Ce}, \mathrm{Yb}$, and $\mathrm{Th}$ ) we find excellent fits with $\mathrm{R}^{2}$ values from $0.99\left(\mathrm{Nb}\right.$, concentration range $\left.12-18.5 \mu \mathrm{g} \cdot \mathrm{g}^{-1}\right)$ to 0.99 (La, $15-88 \mu \mathrm{g} \cdot \mathrm{g}^{-1}$ ) to 0.999 ( $\mathrm{Ba}, 134$ to $1868 \mu \mathrm{g} \cdot \mathrm{g}^{-1}$ ) showing that, overall, the different rock standards do not show markedly different peak suppressions due to matrix effects for our third-generation Agilent 7700x data.

\subsection{Internal Standardization with $\mathrm{Rh}$ and Sample Dilution}

For the full range of elements studied (Li-U) Figure 3 shows the ERR ratios obtained by normalising the count rates for the DF500 rock digests against the count rate for the internal standard ${ }^{103} \mathrm{Rh}$. By comparing the trends for this figure with those for BCR-1 (Figure 2(A)) and BHVO-1, AGV-1, and G-2 without IS normalisation (Figure 2(B)) it is clear that the broad bands of ERR points are displaced upwards. Bands for BCR-1, BHVO-1 and G-2 are centred around the $E R R=1.0$ value but that for AGV-1 falls higher at around $E R R=1.1$. The same sinuous ERR trend of relatively high or low values for both Rh normalised and non-normalised analyses is present in all the four reference rocks studied; Th

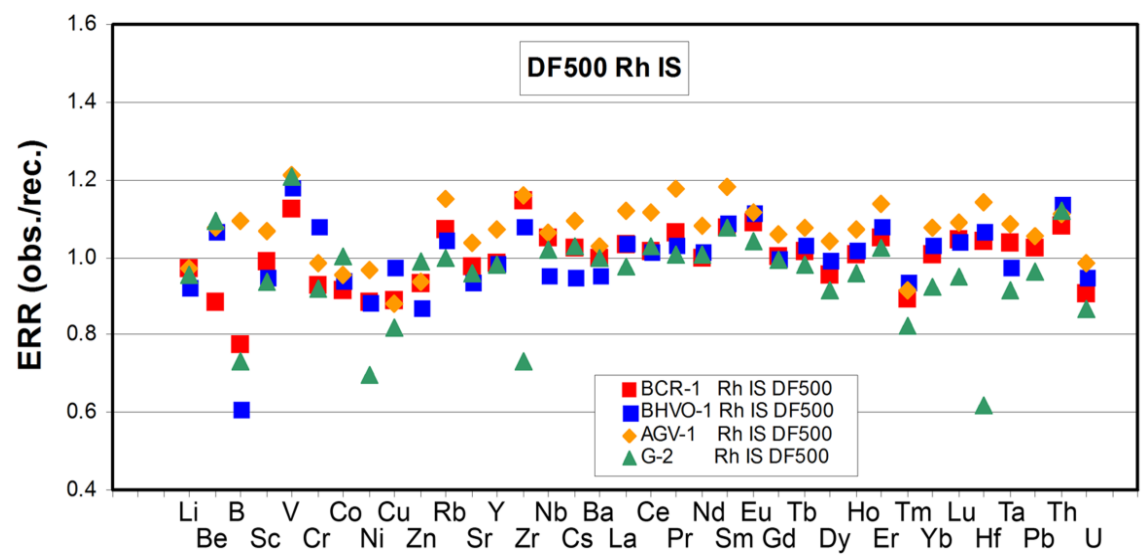

Figure 3. ERR values for DF500 solutions of BCR-1, BHVO-1, AGV-1, and G-2 corrected for ${ }^{103} \mathrm{Rh}$ as the internal standard. Similar sinuous fluctuations are present for each rock but now BCR-1, BHVO-1 and G-2 fall on overlapping, scattered trends centred around $\mathrm{ERR}=1$, while that for AGV-1 is centred at a higher ERR level of 1.1. 
points are uniformly high but $U$ points are now closer to $E R R=1$. Thus our determined concentration levels better match the recommended values when IS corrections are used and ${ }^{103} \mathrm{Rh}$ acts reliably over a wide mass range as an IS except that it over-corrects the suppression for our analyses of AGV-1. Makishima \& Nakamura (1997) found that minimizing matrix effects by the use of high power plasma operating conditions and flow injection gave consistently higher concentrations for AGV-1 compared to recommended values, whereas BCR-1 did not; this is the same relationship to that we report here. It seems that a single IS $\left({ }^{103} \mathrm{Rh}\right)$ serves to correct the peak signal suppression for elements ranging from $\mathrm{Li}$ to $\mathrm{U}$; this was also found in the case of ${ }^{115} \mathrm{In}$ as the lone IS (Pretorius et al., 2006).

Although the DF 500 standard rock digests fall within the recommended total solid concentration ranges the presence of sinuous trends for all rocks show that systematic matrix effects are still present. In a further attempt to minimise peak intensity suppression we diluted the DF 500 solutions to give a series of rock standard solutions with $\mathrm{DF}=5000$. However, these more dilute solutions tend to show higher relative errors for some elements because the concentrations in the diluted solutions are much closer to those for the blanks compared to the values in the DF500 solutions. Nevertheless we consider the ERR data for the full set of elements from $\mathrm{Li}$ to $\mathrm{U}$ but do not report concentrations in tables.

The ERR data for the most dilute solutions for BCR-1, BHVO-1, AGV-1 and G-2 are shown in Figure 4(A) (no IS correction) and Figure 4(B) (Rh IS correction). In Figure 4(A) the data points fall in a horizontal zone centred on ERR = 1.0 with some points for G-2 falling slightly below the other sample trends. It is clear that the scale of count-rate suppression is much smaller for more dilute solutions as has been shown by other researchers (e.g., Makishima \& Nakamura, 1997; Ardini et al., 2010) [see earlier Section 3.2]. The low estimates of ERR values for $\mathrm{Ni}$ and $\mathrm{Cu}$ reflect low element counts and high blank values; the blank cps/sample cps (as \%) are $\sim 30 \%$ and $70 \%$, respectively. We have already identified other mismatches (e.g., low Zr and Hf in G-2, high Zr in the other three standards, and generally low Tm). The Rh corrected data are shown in Figure 4 (B) and show that all four sample trends fall close to ERR $=1.0$ with the same sort of mismatches to those reported for Figure 4(A). It is clear that both sample dilution and internal standardisation with ${ }^{103} \mathrm{Rh}$ are equally successful in normalising the ERR trends to be distributed in a band centred close to ERR $=1.0$ but the same spread of values tends to be present for each solution/normalisation technique used; however, the diluted samples do seem to show a less obvious sinuous structure suggesting that the matrix effect responsible for this has been somewhat suppressed. The fact that Rh normalisation for DF500 solutions and the dilution of those to DF5000 give ERR values for HFSE and REE elements generally close to 1.0 confirms our conclusion above that separation of HFSE from REE elements has not been significant in our rock digestion process and is more consistent with the depleted contents of $\mathrm{Zr}$ and $\mathrm{Hf}$ being due to incomplete 

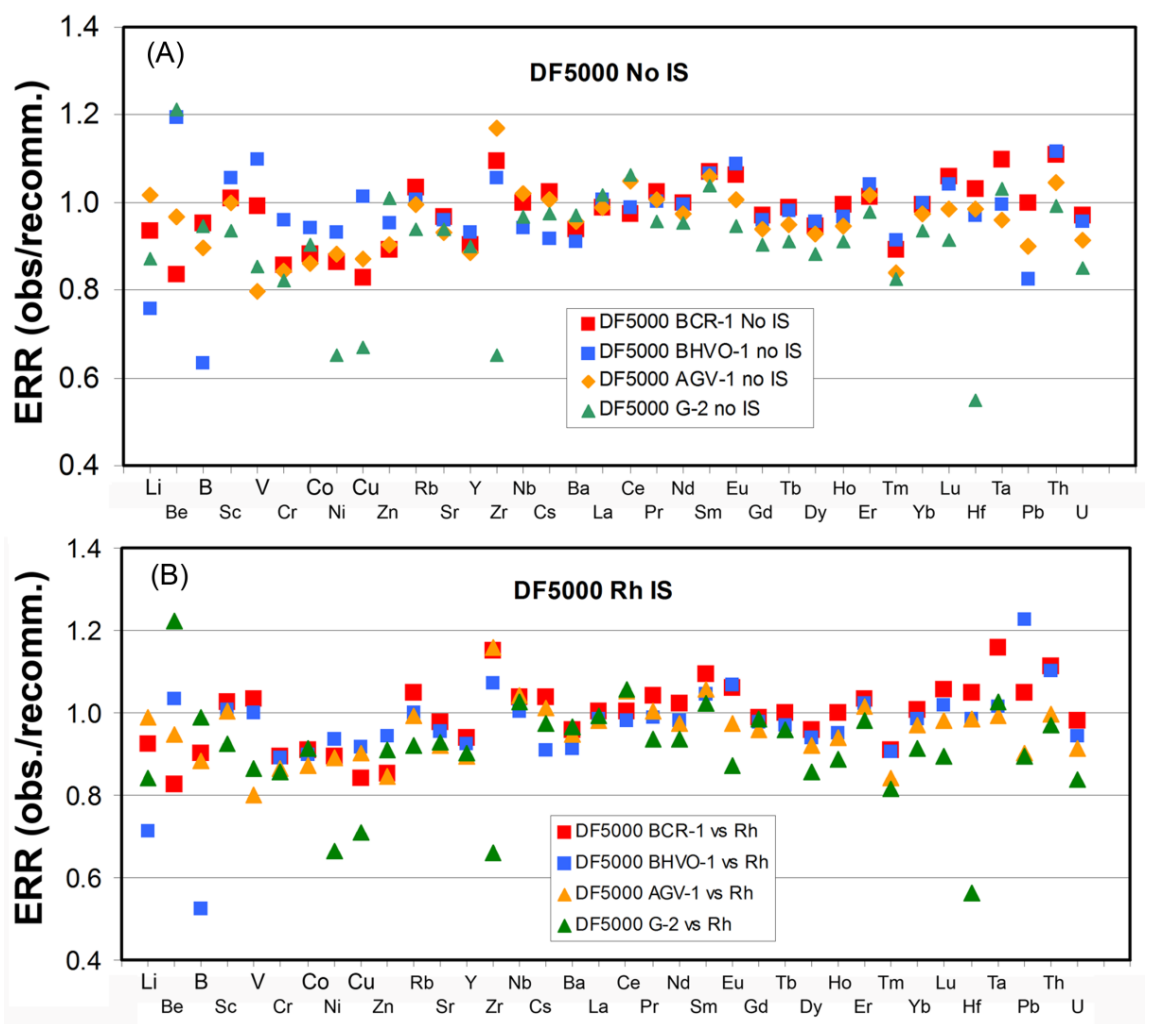

Figure 4. ERR values for $\mathrm{DF}=5000$ solutions of the four standard rocks without internal standard correction (Figure $4(\mathrm{~A})$ ) and with correction versus ${ }^{103} \mathrm{Rh}$ (Figure $4(\mathrm{~B})$ ). Both figures show similar results with elements from $\mathrm{Rb}$ to $\mathrm{U}$ centred around $\mathrm{ERR}=1$ and with many $3 \mathrm{~d}$ elements showing lower values. The higher dilution factor compared to the data shown in Figure 2 and Figure 3 are reflected in lower count rates and higher blanks for some elements in G-2 (e.g., Ni and Cu). The higher dilution has clearly suppressed the matrix effect found for DF500 solutions and correction versus Rh has not had any obvious effect on the element concentration measured.

solution of zircon rather than to hydrolysis and precipitation from a dissolved state (see Section 4.4).

We prefer to adopt the DF 5000 without Rh normalisation as the error propagation only involves two variables (see earlier).

\subsection{Normalising Reference Rock Compositions to a Well-Documented Single External Standard}

Some researchers use well-understood international reference rock analyses rather than synthetic multi-element standard solutions to calibrate count rates for "unknown" samples and to assign concentration levels. For example, Cheatham et al. (1993) used international reference materials (including USGS BHVO-1, W-2, BIR-1, DNC-1, AGV-1, GSP-1, and G-2) as calibration standards but found that sets of basic and acid/intermediate rocks needed to be fitted to separate calibrations (see earlier). Chauvel et al. (2010) used the rock standards basalt BR (CRPG, France) and basalt BHVO-2 to calibrate their analyses for standard igneous and sedimentary rocks treated as unknowns while Schudel et al. (2015) 
calibrated basic rocks with BCR-2 and felsic and intermediate rocks with AGV-2. Thus, we have normalised our average DF500 and DF5000 data for all other samples to our average data for international standard rock BCR-1 using its ERR ratios specific to each element; in effect, the count suppression due to the matrix effect is corrected for each individual element based on the ERR values defined for BCR-1. This latter approach should also correct for systematic and reproducible errors resulting from factors mentioned above.

\subsubsection{Normalisation of Analyses for BHVO-1, AGV-1 and G-2 Using BCR-1}

Figure 5 shows the effect of normalising data for each element in BHVO-1, AGV-1 and G-2 to the specific ERR for each element in BCR-1 (ratios defined in the first column of Table 4). The serious mismatches for $\mathrm{B}$ and $\mathrm{Pb}$ in all three standards and of Zr and Hf in G-2 are still clear. The other data points are centred about 1.0, show ratios for $\mathrm{Zr}$, Th, Dy and Tm close to 1.0 and even most of the $3 \mathrm{~d}$ elements plot much nearer to an ERR $=1.0$ than before. However, note that Schudel et al. (2015) commented that the "Agilent 7700x had difficulty producing reproducible concentrations for mid-mass (45 - $90 \mathrm{amu}$ ) trace elements across almost all reference materials"; this is the same type of instrument used in our work, the mass range includes all of the $3 \mathrm{~d}$ elements, and it seems that we are not the first workers to experience problems with ICP-MS determination of these transition elements. We conclude that using specific ERR ratios for BCR-1 to normalise the other standards provides a reasonable approach to dealing with any mismatches due either to matrix effects or to other systematic and reproducible errors. For example, because we are using the same synthetic standard solutions for all of our analyses, if our standards for Dy and Tm are not exactly on composition, the same errors will be present in a given rock and in

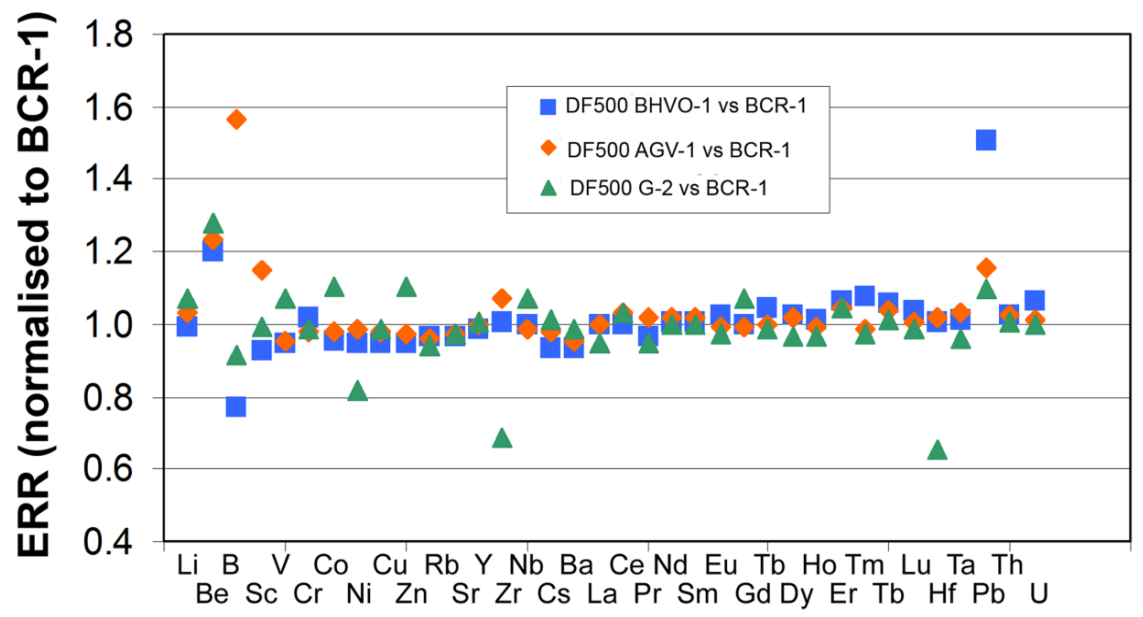

\section{Elements Li to $\mathrm{U}$}

Figure 5. ERR values for DF500 solutions of BHVO-1, AGV-1 and G-2 normalised to our data for the DF500 solution for BCR-1 as the principal external standard. Apart from the scattered points for $\mathrm{Be}, \mathrm{B}$ and $\mathrm{Pb}$ most of the element points fall very close to $\mathrm{ERR}=1$ and even the $3 \mathrm{~d}$ elements show this feature. 
our external BCR-1 reference rock; Figure 5 shows that the corrected ERR points for Dy and Tm do indeed now plot alongside the adjacent REE elements.

Based on the discussions above we suggest that the simplest and most pragmatic approach is to use the DF500 data for all of our samples, without Rh normalisation and we compare the reliability for the different calibration methods by plotting the values for the $z$-scores (Potts et al., 2013) for the full set of elements analysed for BHVO-1 in Figure 6. It is clear that almost all of the $\mathrm{BHVO}-1$ series values from $\mathrm{Rb}$ to $\mathrm{U}$ plot within the acceptable $z$-score range from +2 to -2 although most of the REE points for DF500 with Rh correction plot above the zero line. However the points for $\mathrm{Li}, \mathrm{Be}, \mathrm{B}, \mathrm{Pb}$ and many of the $3 \mathrm{~d}$ element values are clearly more scattered and the same features are shown for the other 3 main reference rocks studied (not figured here). Thus, for the remaining figures we will deal with results from $\mathrm{Rb}$ to $\mathrm{U}$ with the exception of $\mathrm{Pb}$ which is seriously affected by high blanks and contamination. Figure 7 shows $z$-score data for these elements with points for BHVO-1 shown again in Figure $7(\mathrm{~A})$; the only values falling outside the recommended $z$-score range are those for $\mathrm{Ba}$ in the more dilute solutions. Points for AGV-1 are slightly more scattered with generally high $\mathrm{Zr}$ contents (Figure 7(B)); in particular note that the DF500 solutions using $\mathrm{Rh}$ as an IS have been over-corrected with some of the REE having $z$-scores $>+2$. G-2 values are generally acceptable except for the low $\mathrm{Zr}$ and Hf in all solution series (Figure 7(C)); in addition, points for Th in DF500 solutions using $\mathrm{Rh}$ as IS are rather high. Finally, in Figure $7(\mathrm{D})$ we show the data for BCR-1 vs Rh and DF5000 solutions both with and without Rh as IS; data for the DF500 vs Rh series are clearly the most reliable with the DF5000 solutions

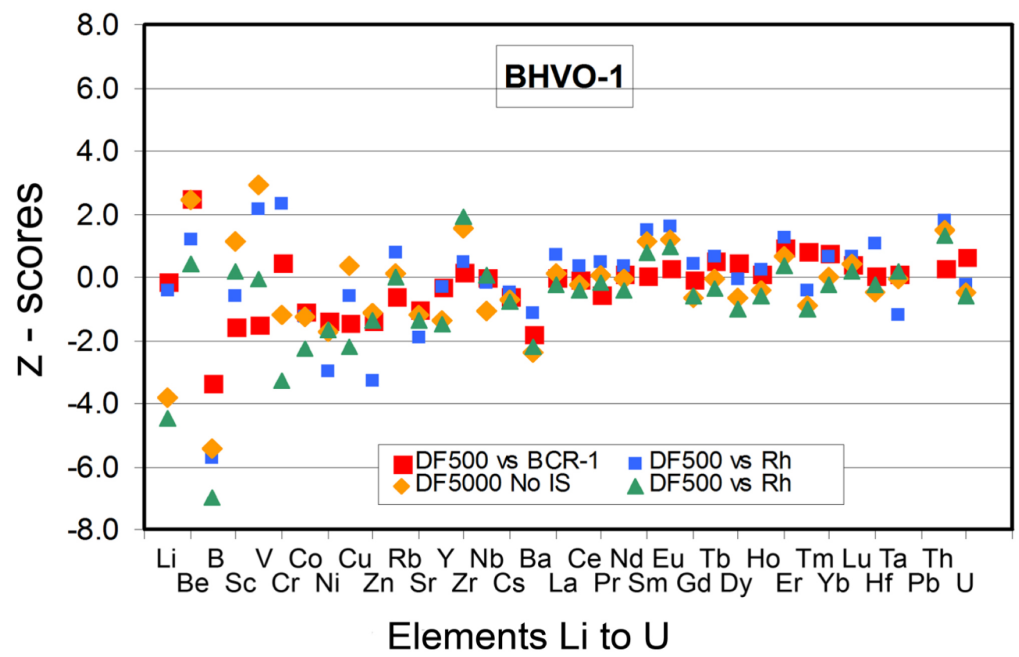

Figure 6. Calculated $z$-scores (Potts et al., 2013) for the different determinations for BHVO-1 show that the vast majority of analyses for $\mathrm{Rb}$ to $\mathrm{U}$ fall within the limits from +2 to -2 and therefore represent "acceptable" data. Only $\mathrm{Pb}$ falls clearly outside this range reflecting problems with sample contamination and high, variable blanks. Some points for $3 \mathrm{~d}$ elements fall outside this range while anomalously low values for $\mathrm{Li}$ and $\mathrm{B}$ reflect higher errors at higher dilutions and/or unreliable "recommended" concentrations. 

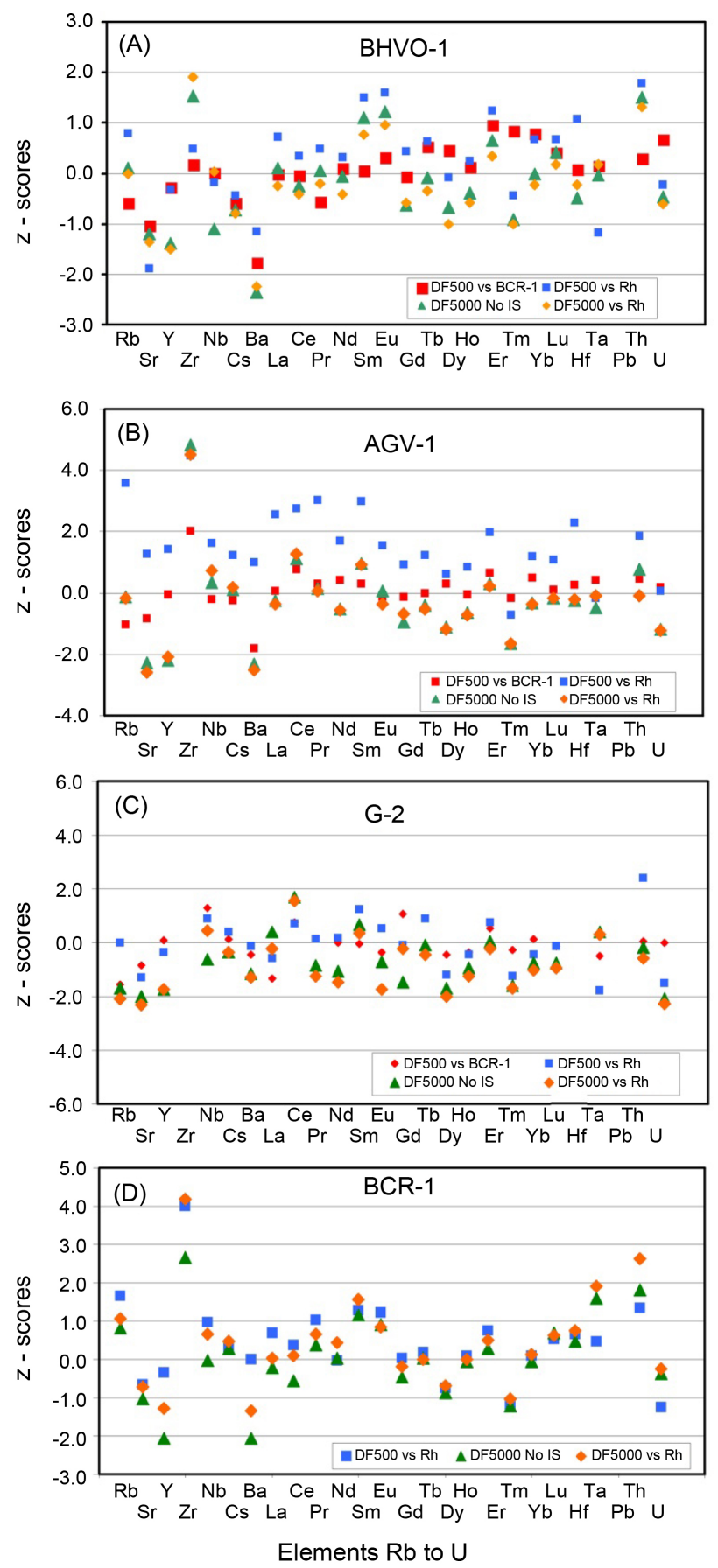

Figure 7. In Figure 7(A)-(C) the calculated $z$-scores (Potts et al., 2013) are shown for elements from Rb to U in BHVO-1, AGV-1, and G-2 for DF500 versus BCR-1, DF500 vs $\mathrm{Rh}, \mathrm{DF} 5000$ no IS, and DF5000 vs Rh. Figure 7(D) shows the $z$-scores for BCR-1 for DF500 vs Rh, DF5000 no IS and DF5000 vs Rh. In all panels the data points fall in a broad band close to $z=0$ and the vast majority fall within the acceptable limits of $z$ from +2 to -2 . Note that BHVO-1 points for DF500 vs Rh mainly fall in a band slightly above $z=0$ while those for AGV-1 DF500 vs Rh are uniformly high. The DF5000 solutions mainly show anomalously high $\mathrm{Zr}$ contents (Figure 7(A), Figure 7(B) and Figure 7(D)); points are not shown for $\mathrm{Zr}$ and $\mathrm{Hf}$ in Figure $7(\mathrm{C})$ because of incomplete solution of zircon during the sample preparation. The best fits for z-scores are shown when the DF500 analytical data are normalised to those for BCR-1. 
showing values for $\mathrm{Zr}$, $\mathrm{Ta}$ and $\mathrm{Th}$ that are too high and values for $\mathrm{Y}$ and $\mathrm{Ba}$ that are rather low. Note that $\mathrm{Pb}$ is not shown in these figures because of contamination effects.

In summary, although a dilution factor of DF5000 markedly reduces the peak suppression found in the DF500 solutions the higher dilutions involve much higher errors for the lightest ( $\mathrm{Li}, \mathrm{Be}, \mathrm{B})$ and heaviest $(\mathrm{Ta}, \mathrm{Pb}$, Th and $\mathrm{U}$ ) elements but the $z$-scores for most of those elements still fall within the range from +2 to -2 . However most of the $3 \mathrm{~d}$ elements in the more dilute solutions show much more negative $z$ values and do not provide acceptable concentration estimates. Apart from $\mathrm{Zr}$, almost all of the elements from $\mathrm{Rb}$ to Lu provide robust concentration estimates; in particular note that the REE show very low $Z$-scores in all four rock standards. It is clear that sample dilution is a very effective way of reducing matrix effect; this observation is in line with one of the principle conclusions of Yokoyama et al. (2016).

Based on the results discussed above we prefer to adopt the DF500 series data normalised against our mean data for BCR-1 as the most reliable set of trace element analyses in our work. While the DF5000 give reasonable estimates for elements $\mathrm{Rb}$ to $\mathrm{Hf}$ without major matrix effects, there are too many problems related to lower counts and higher errors, especially for $\mathrm{Li}, \mathrm{Be}, \mathrm{B}$, and many of the $3 \mathrm{~d}$ elements.

\subsubsection{Results Adopted in This Work for BCR-2, STM-1 and CAAS-1 Normalised to BCR-1}

We will use this approach to assign our most reliable compositions for two standard rocks which lack reliable recommended values for many elements. One is a nepheline syenite (USGS STM-1) and the other a quartz syenite (Canadian sample CAAS-1). We also give our values for another well-known reference sample BCR-2. For these three rocks Table 5 gives our averages for the DF500 series calibrated against BCR-1; robust recommended values are only available for BCR-2 so $z$-scores are only given for that rock. Although STM-1 has been fairly widely studied, particularly for REE, the GeoREM database does not include that sample and the "recommended" data given in Table 5 have been compiled by us from a literature search as described above in Section 3.1 but note that the published data for $3 \mathrm{~d}$ elements are generally patchy. Few workers have studied CAAS-1 in recent years and this rock standard is no longer available but we have included it in our present study because of its exceptional enrichment in rare elements which is relevant to our research on syenite petrogenesis.

Our analyses for BCR-2 from $\mathrm{Rb}$ to $\mathrm{U}$ have acceptable $z$ scores except for marginally low Ba value and high $\mathrm{Zr}$ values. In addition $\mathrm{B}$ and many of the $3 \mathrm{~d}$ elements show the same sort of mismatches that we have already reported. Recent published work on STM-1 has been mainly concentrated on the REE and our new data are in excellent agreement with those values. This rock has generally low contents of $3 \mathrm{~d}$ trace elements and very few reliable analyses have been 
C. M. B. Henderson et al.

Table 5. Adopted trace element concentrations for DF500 solutions of international reference rocks BCR-2, STM-1, and CAAS-1 calibrated against international reference BCR-1.

\begin{tabular}{|c|c|c|c|c|c|c|c|c|c|c|c|c|c|}
\hline & \multicolumn{5}{|c|}{ BCR-2 } & \multicolumn{4}{|c|}{ STM-1 } & \multicolumn{4}{|c|}{ CAAS-1 } \\
\hline & Av. of 2 & $\begin{array}{l}\text { Prop. } \\
\text { error }\end{array}$ & Recomm. & Ratio & $Z$-score & Av. of 3 & $\begin{array}{l}\text { Prop. } \\
\text { error }\end{array}$ & Recomm. & Ratio & Av. of 3 & $\begin{array}{l}\text { Prop. } \\
\text { error }\end{array}$ & Recomm. & Ratio \\
\hline & $\mu \mathrm{g} \cdot \mathrm{g}^{-1}$ & $\mu \mathrm{g} \cdot \mathrm{g}^{-1}$ & $\mu \mathrm{g} \cdot \mathrm{g}^{-1}$ & & & $\mu \mathrm{g} \cdot \mathrm{g}^{-1}$ & $\mu \mathrm{g} \cdot \mathrm{g}^{-1}$ & $\mu \mathrm{g} \cdot \mathrm{g}^{-1}$ & & $\mu \mathrm{g} \cdot \mathrm{g}^{-1}$ & $\mu \mathrm{g} \cdot \mathrm{g}^{-1}$ & $\mu \mathrm{g} \cdot \mathrm{g}^{-1}$ & \\
\hline $\mathrm{Li}$ & 9.46 & 0.43 & 9.13 & 1.04 & 0.62 & 38.2 & 1.87 & 34.75 & 1.10 & 100 & 6.68 & 121 & 0.83 \\
\hline $\mathrm{Be}$ & 2.50 & 0.41 & 2.17 & 1.15 & 2.14 & 12.6 & 1.56 & 9.92 & 1.27 & 34.3 & 4.64 & 26 & 1.32 \\
\hline B & 7.28 & 3.61 & 4.40 & 1.66 & 10.24 & 9.90 & 5.00 & 6.49 & 1.53 & 123 & 61.15 & 100 & 1.23 \\
\hline $\mathrm{Sc}$ & 39.6 & 1.16 & 33.53 & 1.18 & 3.84 & 0.87 & 0.57 & 0.83 & 1.05 & 11.9 & 0.97 & 14 & 0.85 \\
\hline $\mathrm{V}$ & 459 & 7.51 & 417.60 & 1.10 & 3.45 & 0.32 & 0.01 & 4.45 & 0.07 & 96 & 3.38 & 93 & 1.04 \\
\hline $\mathrm{Cr}$ & 16.4 & 1.91 & 15.85 & 1.04 & 0.15 & 1.34 & 0.19 & 3.31 & 0.40 & 52 & 7.13 & 56 & 0.94 \\
\hline $\mathrm{Co}$ & 37.6 & 1.28 & 37.33 & 1.01 & 0.15 & 0.72 & 0.04 & 1.33 & 0.54 & 16.9 & 1.18 & 21 & 0.81 \\
\hline $\mathrm{Ni}$ & 10.71 & 0.90 & 12.57 & 0.85 & -3.09 & 0.83 & 0.07 & 2.25 & 0.37 & 34.8 & 3.78 & 41 & 0.85 \\
\hline $\mathrm{Cu}$ & 17.5 & 1.91 & 19.66 & 0.89 & -2.18 & 2.53 & 0.29 & 4.00 & 0.63 & 15.9 & 1.74 & 21 & 0.76 \\
\hline $\mathrm{Zn}$ & 139 & 7.22 & 129.50 & 1.08 & 1.97 & 247 & 9.11 & 223.60 & 1.10 & 265 & 13.27 & 252 & 1.05 \\
\hline $\mathrm{Rb}$ & 46.6 & 1.22 & 46.02 & 1.01 & 0.58 & 111 & 3.25 & 116.70 & 0.95 & 157 & 8.49 & 195 & 0.81 \\
\hline $\mathrm{Sr}$ & 344 & 8.00 & 337.40 & 1.02 & 0.55 & 675 & 31.19 & 700.00 & 0.96 & 221 & 16.29 & 238 & 0.93 \\
\hline $\mathrm{Y}$ & 37.5 & 0.86 & 36.07 & 1.04 & 0.83 & 46.5 & 1.16 & 48.00 & 0.97 & 502 & 24.33 & 433 & 1.16 \\
\hline $\mathrm{Zr}$ & 206 & 3.74 & 186.50 & 1.10 & 3.23 & 1404 & 33.82 & 1302.00 & 1.08 & 4058 & 123.12 & 3030 & 1.34 \\
\hline $\mathrm{Nb}$ & 12.7 & 0.26 & 12.44 & 1.02 & 0.45 & 270 & 5.57 & 275.20 & 0.98 & 191 & 19.03 & 150 & 1.27 \\
\hline Cs & 1.06 & 0.03 & 1.16 & 0.91 & -1.12 & 1.46 & 0.07 & 1.53 & 0.95 & 1.37 & 0.08 & $?$ & $?$ \\
\hline $\mathrm{Ba}$ & 659 & 22.09 & 683.90 & 0.95 & -2.09 & 558 & 19.08 & 577.00 & 0.97 & 310 & 22.47 & 282 & 1.10 \\
\hline $\mathrm{La}$ & 25.3 & 0.68 & 25.08 & 1.01 & 0.21 & 138 & 10.28 & 150.70 & 0.92 & 166 & 5.56 & 233 & 0.71 \\
\hline $\mathrm{Ce}$ & 54.7 & 0.51 & 53.12 & 1.03 & 0.71 & 267 & 3.04 & 260.00 & 1.03 & 460 & 10.33 & 512 & 0.90 \\
\hline $\operatorname{Pr}$ & 6.63 & 0.10 & 6.83 & 0.97 & -0.47 & 23.9 & 1.71 & 23.40 & 1.02 & 61 & 1.03 & 138 & 0.44 \\
\hline $\mathrm{Nd}$ & 30.2 & 0.60 & 28.26 & 1.07 & 1.40 & 83.3 & 5.09 & 81.20 & 1.03 & 254 & 5.93 & 314 & 0.81 \\
\hline $\mathrm{Sm}$ & 6.68 & 0.12 & 6.55 & 1.02 & 0.34 & 11.7 & 0.72 & 12.70 & 0.92 & 60 & 1.10 & 245 & 0.25 \\
\hline $\mathrm{Eu}$ & 1.90 & 0.03 & 1.99 & 0.97 & -0.66 & 3.32 & 0.22 & 3.49 & 0.92 & 9.12 & 0.33 & 8.0 & 1.12 \\
\hline $\mathrm{Gd}$ & 6.70 & 0.08 & 6.81 & 0.99 & -0.07 & 8.82 & 0.52 & 9.38 & 0.99 & 66 & 1.10 & 58 & 1.13 \\
\hline $\mathrm{Tb}$ & 1.01 & 0.02 & 1.08 & 0.94 & -0.79 & 1.38 & 0.08 & 1.51 & 0.92 & 12.1 & 0.32 & 10 & 1.22 \\
\hline Dy & 6.20 & 0.16 & 6.42 & 0.98 & -0.57 & 7.84 & 0.31 & 8.33 & 0.95 & 86 & 2.40 & 100 & 0.86 \\
\hline Ho & 1.23 & 0.03 & 1.31 & 0.94 & -0.80 & 1.46 & 0.05 & 1.71 & 0.85 & 19.3 & 0.50 & 21 & 0.92 \\
\hline Er & 3.53 & 0.09 & 3.67 & 0.96 & -0.59 & 4.32 & 0.16 & 4.38 & 0.98 & 63 & 1.79 & 57 & 1.11 \\
\hline $\mathrm{Tm}$ & 0.52 & 0.02 & 0.53 & 0.97 & -0.33 & 0.66 & 0.02 & 0.71 & 0.92 & 10.2 & 0.33 & 5.0 & 2.04 \\
\hline $\mathrm{Yb}$ & 3.29 & 0.09 & 3.39 & 0.97 & -0.46 & 4.33 & 0.14 & 4.43 & 0.96 & 63.2 & 1.79 & 60 & 1.05 \\
\hline $\mathrm{Lu}$ & 0.52 & 0.01 & 0.50 & 1.02 & 0.23 & 0.63 & 0.02 & 0.62 & 1.01 & 8.93 & 0.28 & 1.5 & 5.95 \\
\hline $\mathrm{Hf}$ & 4.53 & 0.12 & 4.97 & 0.91 & -1.42 & 29.5 & 0.97 & 28.53 & 1.04 & 72 & 2.90 & $?$ & $?$ \\
\hline $\mathrm{Ta}$ & 0.74 & 0.03 & 0.79 & 0.95 & 0.09 & 18.6 & 0.58 & 18.75 & 0.95 & 9.23 & 1.49 & $?$ & $?$ \\
\hline $\mathrm{Pb}$ & 9.41 & 0.67 & 10.59 & 0.89 & -1.98 & 16.7 & 1.32 & 17.70 & 0.95 & 106 & 11.52 & 495 & 0.21 \\
\hline Th & 5.50 & 0.30 & 5.83 & 0.94 & -0.28 & 37.6 & 3.62 & 30.80 & 1.22 & 1158 & 62.07 & 1305 & 0.89 \\
\hline $\mathrm{U}$ & 1.51 & 0.06 & 1.68 & 0.89 & -1.42 & 8.99 & 0.38 & 8.76 & 1.03 & 2192 & 135.40 & 2521 & 0.87 \\
\hline
\end{tabular}


recorded. However, the very high $\mathrm{Zr}$ content $\left(1300-1400 \mu \mathrm{g} \cdot \mathrm{g}^{-1}\right)$ combined with low Sc content leads to a large correction for doubly charged ${ }^{90} \mathrm{Zr}$ on the only isotope of $\mathrm{Sc}\left({ }^{45} \mathrm{Sc}\right)$ when using ICP-MS. We suggest that our data for this rock should be useful in moving towards a recommended data set. Finally, the rare element enrichments shown by the Canadian syenite CAAS- 1 are remarkable, with $\sim 30 \mu \mathrm{g} \cdot \mathrm{g}^{-1} \mathrm{Be}, 4000 \mu \mathrm{g} \cdot \mathrm{g}^{-1} \mathrm{Zr}, 460 \mu \mathrm{g} \cdot \mathrm{g}^{-1} \mathrm{Ce}, 1150 \mu \mathrm{g} \cdot \mathrm{g}^{-1} \mathrm{Th}$, and $2200 \mu \mathrm{g} \cdot \mathrm{g}^{-1}$ U. Our dataset for REE in this rock is more complete than values published so far. We hope that laboratories that still possess a supply of this rock will find our new data useful.

\subsubsection{Testing the Oxide and Hydroxide Interference Corrections for Ba and LREE Necessary for Obtaining Reliable Analyses for Eu, Gd and Other Heavier REE}

In this final section we assess the scale these molecular interferences have on REE determination using three Marangudzi complex rocks chosen because of their very high $\mathrm{Ba}$ contents and/or elevated REE values. ICP-MS analyses of these three rocks were first obtained in 2017 (run 6717) using DF500 solutions and the adopted concentrations were normalised to the BCR-1 data determined during those runs (see Section 4.6). In the 2018 analysis batch (run 6918) three of the original samples were diluted to DF1000 and run in duplicate as described earlier. The 2017 analyses should be the more reliable but it is informative to compare the results of the REE correction calculation between those and the new data. Note that the 2017 and 2018 analyses will require different REE peak-interference correction factors as explained in Section 4.3 and these were calibrated using the appropriate equations (see Section 4.3) and measured $\mathrm{CeO} / \mathrm{Ce}$ ratios.

The three rocks are a biotite-rich syenogabbro (R.19), a plagioclase-bearing syenite (pulaskite, R.26) and a nepheline-rich syenite (foyaite, R.226). Table 6 gives the concentrations for the full element suite, normalised to the relevant average BCR-1 data and also corrected for REE interferences. Despite the 2018 analyses having been carried out with 12 month old solutions the two sets of analyses for R.19 and R.26 and for the lower mass elements in R.226 show very good agreement overall. However, for R.226 elements from Ba up to U the 2018 analyses are consistently higher than those determined in 2017. The main thrust of these analyses was to assess the reliability of the corrections made to some of the REE and in this regard note that the oxide and hydroxide corrections are different for the 2017 and 2018 experiments because the plasma conditions are different (see Section 4.3). In particular note the Ba concentrations of $\sim 1.33 \%$ in R. 19 and $\sim 0.5 \%$ in R. 26 coupled with low Eu in those rocks. Thus the corrections necessary for these rocks can best be shown comparing the corrected values (Table 6) with the equivalent isotope values uncorrected for the relevant interferences (given below, units $\mu \mathrm{g} \cdot \mathrm{g}^{-1}$ ):

${ }^{137} \mathrm{BaO}$ and ${ }^{136} \mathrm{BaOH}$ on ${ }^{153} \mathrm{Eu}$ :

6717, R.19 Eu (uncorr.) 4.41 (36\% reduction); R26 Eu (uncorr.) 3.56 (13\% reduction) 
C. M. B. Henderson et al.

Table 6. ICP-MS analyses for Marangudzi rocks corrected against BCR-1 data obtained in the same batches and also corrected for REE spectral interferences. Data are given for 2017 (run 6717) and 2018 (run 6918).

\begin{tabular}{|c|c|c|c|c|c|c|}
\hline & \multicolumn{2}{|c|}{ R.19 } & \multicolumn{2}{|c|}{ R.26 } & \multicolumn{2}{|c|}{ R.226 } \\
\hline & 2017 & 2018 & 2017 & 2018 & 2017 & 2018 \\
\hline & $\mu \mathrm{g} \cdot \mathrm{g}^{-1}$ & $\mu \mathrm{g} \cdot \mathrm{g}^{-1}$ & $\mu \mathrm{g} \cdot \mathrm{g}^{-1}$ & $\mu \mathrm{g} \cdot \mathrm{g}^{-1}$ & $\mu \mathrm{g} \cdot \mathrm{g}^{-1}$ & $\mu \mathrm{g} \cdot \mathrm{g}^{-1}$ \\
\hline Li BCR & 6.60 & 6.74 & 6.76 & 7.70 & 9.14 & 9.97 \\
\hline Be BCR & 0.76 & 0.47 & 2.79 & 1.64 & 4.55 & 2.69 \\
\hline B BCR & 1.09 & 0.89 & 2.84 & 2.18 & 11.1 & 6.84 \\
\hline Sc BCR & 11.5 & 10.6 & 4.59 & 4.05 & 1.18 & 0.67 \\
\hline V BCR & 208 & 206 & 33.2 & 29.0 & 2.60 & 2.75 \\
\hline Cr BCR & 6.02 & 5.61 & 9.90 & 8.40 & 0.38 & 0.25 \\
\hline Co BCR & 29.3 & 25.5 & 47.8 & 44.9 & 25.4 & 22.1 \\
\hline $\mathrm{Ni}$ BCR & 9.91 & 9.66 & 7.21 & 6.79 & 0.90 & 0.88 \\
\hline $\mathrm{Cu}$ BCR & 30.0 & 31.8 & 30.0 & 23.4 & 7.90 & 8.35 \\
\hline $\mathrm{Zn} \mathrm{BCR}$ & 67.0 & 62.0 & 89.8 & 84.47 & 80.5 & 75.9 \\
\hline $\mathrm{Rb} B C R$ & 305 & 342 & 209 & 227 & 241 & 269 \\
\hline Sr BCR & 2253 & 2245 & 1204 & 1178 & 25.1 & 34.7 \\
\hline Y BCR & 18.4 & 18.4 & 31.4 & 30.9 & 45.4 & 53.0 \\
\hline $\mathrm{Zr}$ BCR & 60.0 & 59.2 & 148 & 142 & 123 & 118 \\
\hline $\mathrm{Nb}$ BCR & 37.4 & 38.8 & 205 & 206 & 84 & 83 \\
\hline Cs BCR & 3.78 & 3.78 & 2.30 & 2.27 & 1.56 & 1.56 \\
\hline Ba BCR & 13286 & 13095 & 4831 & 4678 & 64.5 & 73.5 \\
\hline La BCR & 71.7 & 72.5 & 125 & 123 & 123 & 182 \\
\hline Ce BCR & 141 & 138 & 235 & 226 & 523 & 533 \\
\hline Pr BCR & 16.2 & 16.9 & 24.3 & 25.2 & 23.9 & 34.3 \\
\hline $\mathrm{Nd} \mathrm{BCR}$ & 65.0 & 62.9 & 87 & 92 & 81 & 125 \\
\hline Sm BCR & 8.31 & 8.76 & 10.4 & 10.9 & 10.1 & 13.5 \\
\hline $\mathrm{Eu}$ BCR & 2.88 & 2.55 & 3.10 & 3.00 & 1.03 & 1.40 \\
\hline Gd BCR & 6.29 & 5.62 & 8.00 & 7.26 & 10.5 & 11.3 \\
\hline $\mathrm{Tb}$ BCR & 0.63 & 0.66 & 0.92 & 0.90 & 1.12 & 1.27 \\
\hline Dy BCR & 3.20 & 3.26 & 4.79 & 4.90 & 5.89 & 7.03 \\
\hline Ho BCR & 0.60 & 0.61 & 0.88 & 0.99 & 1.05 & 1.46 \\
\hline Er BCR & 1.74 & 1.70 & 3.05 & 3.02 & 4.00 & 4.52 \\
\hline Tm BCR & 0.22 & 0.23 & 0.45 & 0.46 & 0.58 & 0.67 \\
\hline $\mathrm{Yb} B C R$ & 1.38 & 1.39 & 2.99 & 3.00 & 3.51 & 3.91 \\
\hline Lu BCR & 0.22 & 0.22 & 0.49 & 0.48 & 0.51 & 0.56 \\
\hline Hf BCR & 1.29 & 1.34 & 2.76 & 2.91 & 1.76 & 1.99 \\
\hline Ta BCR & 1.58 & 1.56 & 8.29 & 7.04 & 3.52 & 3.74 \\
\hline $\mathrm{Pb}$ BCR & 3.44 & 3.51 & 24.0 & 30.1 & 20.5 & 29.6 \\
\hline Th BCR & 4.60 & 4.66 & 13.0 & 11.3 & 40.0 & 90.4 \\
\hline U BCR & 0.69 & 0.76 & 1.63 & 1.86 & 6.47 & 8.81 \\
\hline
\end{tabular}


5917, R.19 Eu (uncorr.) 3.68 (32\% reduction), R26 Eu (uncorr.) 3.39 (13\% reduction)

The use of the ${ }^{151} \mathrm{Eu}$ isotope to analyse for Eu would also be subject to interferences from $\mathrm{Ba}$, in that case from ${ }^{135} \mathrm{BaO}$ and ${ }^{134} \mathrm{BaOH}$.

${ }^{141} \mathrm{PrO}$ and ${ }^{140} \mathrm{CeO}$ on ${ }^{157} \mathrm{Gd}$ :

6717, R.19 Gd (uncorr.) 6.95 (11\% reduction); R26 Gd (uncorr.) 11.48 (9\% reduction)

5917, R.19 Gd (uncorr.) 6.55 (15\% reduction), R26 Gd (uncorr.) 8.68 (7\% reduction)

${ }^{156} \mathrm{GdO}$ on ${ }^{172} \mathrm{Yb}$ :

6717, R.19 Yb (uncorr.) 1.45 (5\% reduction); R26 Yb (uncorr.) 3.13 (4\% reduction)

5917, R.19 Yb (uncorr.) 1.42 (2\% reduction), R26 Gd (uncorr.) 3.04 (1.5\% reduction)

Bearing in mind the experimental uncertainties these values show reasonably good agreement. Other interferences are present but are less significant and decrease as the bond strength of the REE-O decreases as indicated earlier (Section 4.3 and Dulski, 1994).

Although the determination of absolute concentrations for some REE isotopes depend crucially on the reliability of the correction factors, the impact of any inadequate corrections on petrological considerations would depend on the appearance of the trends in chondrite normalised plots, in particular on the presence of positive or negative $\mathrm{Eu}$ anomalies. Thus Figure 8 shows the trends for the three rocks separately with each panel showing the data trends for 2017 (6717), 2018 (6918) with corrected REE data, and 2018 (6918) data with uncorrected REE values. Figure 8(A) (R.19) shows excellent agreement for the corrected data for both the main data sets for R.19 without a significant Eu anomaly. However, the data points for uncorrected $\mathrm{Eu}$ and $\mathrm{Gd}$ are both displaced to higher values and indeed the $\mathrm{Eu}$ in this rock shows an apparent small positive Eu anomaly. The uncorrected points for the heavier REE all overplot the corrected points. Figure 8 (B) shows good agreement for the two main data sets for R.26 and that the uncorrected data points for $\mathrm{Eu}$ and Gd both plot only slightly above their corrected values. Figure 8(C) for R.226 shows clearly that, except for Ce, the 2018 analyses are consistently displaced upwards from the values for the 2017 analyses. However, the overall appearance is the same with clear negative Eu anomalies and a clear positive anomaly for Ce, particularly for the 2017 data set. Note also that the uncorrected point for Eu overlies the corrected point for the 2018 data which reflects the very low Ba content in this rock while the uncorrected 2018 point for Gd is displaced to higher values from the corrected point reflecting the effect of the high Ce content (as ${ }^{140} \mathrm{CeOH}$ ) on the determination of ${ }^{157} \mathrm{Gd}$.

Although most peak interferences on REE determinations appear to be less obvious when using chondrite normalised plots with logarithmic composition scales, it is necessary to consider the possible effects, especially for alkali igneous 

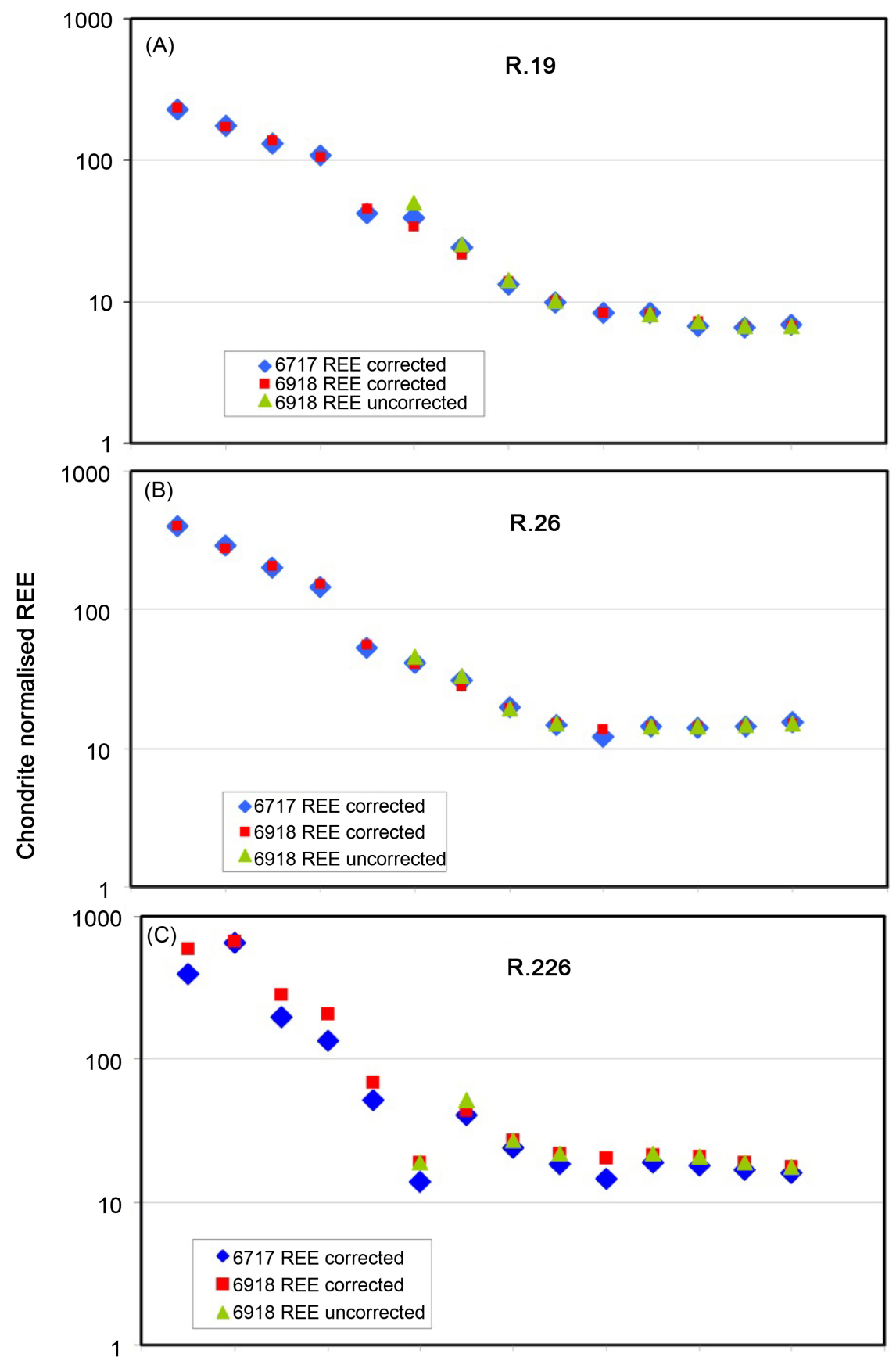

La Ce Pr Nd Sm Eu Gd Tb Dy Ho Er Tm Yb Lu

\section{Rare earth elements}

Figure 8. Chondrite normalised plots are shown for three rocks from the Marangudzi Igneous Complex, Zimbabwe in separate panels. Figure 8(A) shows data for biotite-rich syenogabbro R.19, Figure 8(B) data for plagioclase-bearing, nepheline-poor syenite R.26, and Figure $8 \mathrm{C}$ the data for the most differentiated nepheline syenite R.226. Data used are BCR-1 normalised analyses also corrected for $\mathrm{Ba}$ and REE interferences for the three rocks analysed in 2017 and 2018. Also shown are the 2018 data for Eu and Gd without correction for the appropriate interferences (e.g., ${ }^{137} \mathrm{BaO}$ on ${ }^{153} \mathrm{Eu}$, and ${ }^{141} \mathrm{PrO}$ and ${ }^{141} \mathrm{CeOH}$ on ${ }^{157} \mathrm{Gd}$ ). Note the presence of negative $\mathrm{Eu}$ and positive $\mathrm{Ce}$ anomalies in the most differentiated rock-type R.226. 
rock series enriched in REE; relative proportions of key pairs of REE elements are as important as absolute concentrations. The steeper the REE trend, the greater would be the effect of interferences which the more abundant LREE would have on the heavier, less abundant HREE.

\section{Conclusion}

1) Despite using solutions prepared from international reference basalts, andesite and granite within the approved TDS range ( 350 - $680 \mathrm{ppm})$, with "robust plasma" operating conditions at high power (1550 W), and using a He-filled octopole collision cell, element peak, matrix suppression effects still reduced peak signals by an average of $\sim 10 \%$ for all rock types, although there was no clear dependence on mass from ${ }^{7} \mathrm{Li}$ to ${ }^{238} \mathrm{U}$.

2) DF500 analyses for BHVO-1, AGV-1 and G-2 calibrated against our analyses for BCR-1 provide our most reliable data for these three rocks, in particular for the REE but for most of the $3 \mathrm{~d}$ elements as well. Indeed this approach is consistent with the need to establish the "traceability" of the analysis standardisation protocol, consistent with the International Organization for Standardisation guidance (ISO/IEC 17025; Wood, 2008). On this calibration basis, we also present our suggested analyses for the other reference materials BCR-2, STM-1 and CAAS-1 the last two of which have not been listed in GeoREM.

3) None of the analyses for the rocks studied show the effects of separation of $\mathrm{REE}$ from $\mathrm{Zr}, \mathrm{Hf}, \mathrm{Nb}$ and $\mathrm{Ta}$ due to the precipitation and/or removal of insoluble fluorides. However, for granitic rocks zircon was not completely digested and in our ongoing research on alkaline felsic rocks we prefer to use XRF data for zircon-bearing rock types.

4) Our new analyses and published data (Dulski, 1994) for the proportions of oxides and hydroxide for $\mathrm{Ba}$ and representative REEs in the plasma have allowed correction factors to be refined for the important interferences of ${ }^{137} \mathrm{Ba}^{16} \mathrm{O}$ with ${ }^{153} \mathrm{Eu}$ and of ${ }^{141} \mathrm{Pr}^{16} \mathrm{O}$ and ${ }^{140} \mathrm{Ce}^{16} \mathrm{O}^{1} \mathrm{H}$ with ${ }^{157} \mathrm{Gd}$ as long as each ICP-MS run is calibrated to obtain the ${ }^{140} \mathrm{CeO} / \mathrm{Ce}$ ratio. $\mathrm{Ba}$ - and REE-rich undersaturated igneous rocks are used to show that the scale of the interferences on Eu and Gd can be as high as $35 \%$ for the ${ }^{153} \mathrm{Eu}$ signal and $15 \%$ for ${ }^{157} \mathrm{Gd}$. For these rock types, the effects of other interferences tend to be $<0.5 \%$ except for ${ }^{156} \mathrm{GdO}$ on ${ }^{172} \mathrm{Yb}$ (up to $2 \%)$.

5) Many of these errors vary systematically. Count rates for ${ }^{103} \mathrm{Rh}$ show small, systematic fluctuations between those for samples, standards and blanks; solutions of the same rock run as adjacent samples sometimes show Rh count-rate variations of $4 \%-5 \%$. We conclude that such variation points to the existence of transient instabilities in one or more of sample introduction, plasma operation, diffusion through the system, and stability of the mass spectrometer and detector system. It seems that a combination of such random and systematic variations introduces an intrinsic error of perhaps $\pm 5 \%$ for ICP-MS analyses of trace elements in aluminosilicate rocks which is difficult or impossible to avoid. 
6) Following the Geo $P T$ proficiency testing approach, calculation of $z$-scores shows that analyses for most of the elements we have studied fall within the acceptable range from $z=+2$ to -2 and show that the compositional differences between our mean analyses and those for the recommended values for BCR-1, BHVO-1, AGV-1, G-2 and BCR-2 are not significant.

\section{Acknowledgements}

We thank Phil Potts for advice regarding Geo $P T$ proficiency testing and dealing with errors, and Nick Pearce for much advice about ICP-MS analyses of igneous rocks and internal standardisation. We also thank Kevin Knight for help with formatting the equations. Any inconsistencies or unreliable conclusions are the responsibility of the authors. CMBH thanks Head of SEES Kevin Taylor for approving and funding the early stages of this research project.

\section{Conflicts of Interest}

None to declare.

\section{References}

Agatemor, C., \& Beauchemin, D. (2011). Matrix Effects in Inductively Couple Plasma Mass Spectrometry: A Review. Analytica Chimica Acta, 706, 66-83. https://doi.org/10.1016/j.aca.2011.08.027

Agilent (2005). ICP-MS, Inductively Coupled Plasma Spectrometry: A Primer (80 p.). Agilent Technologies, Publication Number 5989-3526EN.

Albert, R., \& Horwitz, W. (1997). A Heuristic Derivation of the Horwitz Curve. Analytical Chemistry, 69, 789-790. https://doi.org/10.1021/ac9608376

Alnour, I. A., Wagiran, H., Ibrahim, N., Hamzah, S., Wee, B. S., \& Elias, M. S. (2015). Rare Earth Element Determination and Distribution Patterns in Granite Rock Samples by Using INAA Absolute Method. Journal Radioanalytical Nuclear Chemistry, 303, 1999-2009.

Ardini, F., Soggia, F., Rugi, F., Udisti, R., \& Grotti, M. (2010). Comparison of Inductively Coupled Plasma Spectrometry Techniques for the Direct Determination of Rare Earth Elements in Digests from Geological Samples. Analytica Chimica Acta, 678, 18-25. https://doi.org/10.1016/j.aca.2010.07.036

Balcaen, L., Bolea-Fernandez, E., Resano, M., \& Vanhaecke, F. (2015). Inductively Coupled Plasma-Tandem Mass Spectrometry (ICP-MS/MS): A Powerful and Universal Tool for the Interference-Free Determination of (Ultra)trace Elements-A Tutorial Review. Analytica Chimica Acta, 894, 7-19. https://doi.org/10.1016/j.aca.2015.08.053

Baxter, D. C., Rodushkin, I., \& Engström, E. (2012). Isotope Abundance Ratio Measurements by Inductively Coupled Plasma-Sector Field Mass Spectrometry. Journal Analytical Atomic Spectrometry, 27, 1355-1381. https://doi.org/10.1039/c2ja30153a

Bédard, L., \& Barnes, S.-J. (2002). A Comparison of N-Type Semi-Planar and Coaxial INAA Detectors for 33 Geochemical Reference Samples. Journal Radioanalytical Nuclear Chemistry, 254, 485-497. https://doi.org/10.1023/A:1021685904319

Belousova, E. A., Griffin, W. L., O’Reilly, S. Y., \& Fisher, N. I. (2002). Igneous Zircon Trace Element Composition as an Indicator of Source Rock Type. Contributions to Mineralogy and Petrology, 143, 602-622. https://doi.org/10.1007/s00410-002-0364-7 
Brooks, R. R., Siriwardena, A., \& Lee, J. (1985). A Plasma Emission Method for Determining Elemental Constituents of Geological Materials with a High Iron Content. Chemical Geology, 53, 31-35. https://doi.org/10.1016/0009-2541(85)90018-X

Chauvel, C., Bureau, S., \& Poggi, C. (2010). Comprehensive Chemical and Isotopic Analyses of Basalt and Sediment Reference Materials. Geostandards and Geoanalytical Research, 35, 125-143. https://doi.org/10.1111/j.1751-908X.2010.00086.x

Cheatham, M. M., Sangrey, W. F., \& White, W. M. (1993). Source of Error in External Calibration ICP-MS Analysis of Geological Samples and an Improved Non-Linear Drift Correction Procedure. Spectrochimica Acta, 48B, E487-E506. https://doi.org/10.1016/0584-8547(93)80054-X

D’Orazio, M. (1998). Boron Determination in Twenty One Silicate Rock Reference Materials by Isotope Dilution ICP-MS. Geostandards Newsletter, 23, 21-25. https://doi.org/10.1111/j.1751-908X.1999.tb00556.x

Dai-Kin, F., Prudêncio, M. I., Gouveia, M. A., \& Magnusson, E. (1998). Determination of Rare Earth Elements in Geological Reference Materials: A Comparative Study by INAA and ICP-MS. Geostandards Newsletter, 23, 47-58.

Dulski, P. (1994). Interference of Oxide, Hydroxide and Chloride Analyte Species in the Determination of Rare Earth Elements in Geological Samples by Inductively Coupled Plasma-Mass Spectrometry. Fresnius Journal of Analytical Chemistry, 350, 194-203. https://doi.org/10.1007/BF00322470

Dulski, P. (2001). Reference Materials for Geochemical Studies: New Analytical Data by ICP-MS and Critical Discussion of Reference Values. Geostandards Newsletter, 25, 87-125. https://doi.org/10.1111/j.1751-908X.2001.tb00790.x

Eggins, S. M., Woodhead, J. D., Kinsley, L. J. P., Mortimer, G. E., Sylvester, P., McCulloch, M. T., Hergt, J. M., \& Handler, M. R. (1997). A Simple Method for the Precise Determination of $\geq 40$ Trace Elements in Geological Samples by ICPMS Using Enriched Isotope Internal Standardisation. Chemical Geology, 134, 311-326. https://doi.org/10.1016/S0009-2541(96)00100-3

Evans, E. H., Pisonero, J., Smith, C. M. M., \& Taylor, R. N. (2018). Atomic Spectrometry Update; Review of Advance in Atomic Spectrometry and Related Techniques. Journal Analytical Atomic Spectrometry, 33, 684-705. https://doi.org/10.1039/C8JA90012D

Foland, K. A., Landoll, J. D., Henderson, C. M. B., \& Chen, J. (1993). Formation of Cogenetic Quartz and Nepheline Syenites. Geochimica et Cosmochimica Acta, 57, 697-704. https://doi.org/10.1016/0016-7037(93)90380-F

Fuge, R. (1973). The Automated Photometric Determination of Vanadium in Geological Samples with 4-(2-pyridylazo) Resorcinol. Chemical Geology, 12, 61-68. https://doi.org/10.1016/0009-2541(73)90028-4

Garçon, M., Sauzėat, L., Carlson, R. W., Shirey, S. B., Simon, M., Balter, V., \& Boyet, M. (2017). Nitrile, Latex, Neoprene and Vinyl Gloves: A Primary Source of Contamination for Trace Element and Zn Isotopic Analyses in Geological and Biological Samples. Geostandards and Geoanalytical Research, 41, 367-380. https://doi.org/10.1111/ggr.12161

Gladney, E. S., \& Roelandts, I. (1988). Compilation of Elemental Concentration Values for USGS BHVO-1, Mag-1, QLO-1, RCM-1, SCo-1, SDC-1, SGR-1 and STM-1. Geostandards Newsletter, 12, 253-362. https://doi.org/10.1111/j.1751-908X.1988.tb00053.x

Gouveia, M. A., \& Prudêncio, M. I. (2000). New Data on Sixteen Reference Materials Obtained by INAA. Journal of Radioanalytical and Nuclear Chemistry, 245, 105-108.

Govindaraju, K. (1994). 1994 Compilation of Working Values and Sample Description for 383 Geostandards. Geostandards and Geoanalytical Research, 18, 1-158. 
Henderson, C. M. B., Martin, J. S., \& Mason, R. A. (1989). Compositional Relations in Li-Micas from S.W. England and France: An Ion- and Electron-Microprobe Study. Mineralogical Magazine, 53, 427-449. https://doi.org/10.1180/minmag.1989.053.372.03

Hofmeyr, P. K. (1972). Some Emission Spectrographic Trace Element Data for Reference Silicate Materials. Chemical Geology, 9, 23-28. https://doi.org/10.1016/0009-2541(72)90031-9

Horwitz, H., \& Albert, R. (1995). Precision in Analytical Measurements: Expected Values and Consequences in Geochemical Analyses. Fresnius Journal of Analytical Chemistry, 351, 507-513. https://doi.org/10.1007/BF00322724

Jarvis, K. (1988). Inductively Coupled Plasma Mass Spectrometry: A New Technique for the Rapid or Ultra-Trace Level Determination of the Rare Earth Elements in Geological Materials. Chemical Geology, 68, 31-39. https://doi.org/10.1016/0009-2541(88)90084-8

Jenner, J. A., Longerich, H. P., Jackson, S. E., \& Fryer, B. J. (1990). A Powerful Tool for High-Precision Trace-Element Analysis in Earth Sciences: Evidence from Analysis of Selected U.S.G.S. Reference Samples. Chemical Geology, 83, 133-148. https://doi.org/10.1016/0009-2541(90)90145-W

Jochum, K. P., Weis, U., Schwager, B., Stoll, B., Wilson, S. A., Haug, G. H., Andreae, M. O., \& Enzweiler, J. (2015). Reference Values Following ISO Guidelines for Frequently Requested Rock Reference Materials. Geostandards and Geoanalytical Research, 40, 333-350. https://doi.org/10.1111/j.1751-908X.2015.00392.x

Korotev, R. L. (1996). A Self-Consistent Compilation of Element Concentration Data for 93 Geochemical Reference Samples. Geostandards Newsletter, 20, 217-245. https://doi.org/10.1111/j.1751-908X.1996.tb00185.x

Landoll, J. D. (1994). The Role of Crustal Interactions in the Formation of Cogenetic Silica Oversaturated and Undersaturated Syenites: Evidence from the Alkaline Complexes of Abu Khruq (Egypt), Mt Shefford (Quebec), and Marangudzi (Zimbabwe) (364 p.). PhD Thesis, Columbus, OH: The Ohio State University.

Lin, A., He, M., Hu, S., Yuan, H., \& Gao, S. (2000). Precise Determination of Trace Elements in Geological Samples by ICP-MS Using Compromise Conditions and Fine Matrix-Matching Strategy. Analytical Sciences (Japan), 16, 1291-1296. https://doi.org/10.2116/analsci.16.1291

Linge, K. L., \& Jarvis, K. E. (1997). Quadrupole ICP-MS: Introduction to Instrumentation, Measurement Techniques and Analytical Capabilities. Geostandards and Geoanalytical Research, 33, 445-467. https://doi.org/10.1111/j.1751-908X.2009.00039.x

Linge, K. L., Bédard, L. P., Bugoi, R., Enzweiler, J., Jochum, K. P., Kilian, R., Liu, J., Marin-Carbonne, J., Merchel, S., Munnik, F., Morales, L. F. G., Rollion-Bard, C., Souders, A. K., Sylvester, P. J., \& Weis, U. (2017). GGR Biennial Critical Review: Analytical Developments since 2014. Geostandards and Geoanalytical Research, 41, 493-562. https://doi.org/10.1111/ggr.12200

Linsinger, T. (2010). Comparison of a Measurement Result with the Certified Value. European Reference Materials (ERM), Application Note 1. http://www.erm-crm.org

Longerich, H. P., Fryer, B. J., Strong, D. F., \& Kantipuly, C. J. (1987). Effects of Operating Conditions on the Determination of the Rare Earth Elements by Inductively Coupled Plasma-Mass Spectrometry. Spectrochimica Acta, 42B, 75-92.

https://doi.org/10.1016/0584-8547(87)80051-4

Longerich, H. P., Jenner, G. A., Fryer, B. J., \& Jackson, S. E. (1990). Inductively Coupled Plasma-Mass Spectrometric Analysis of Geological Samples: A Critical Evaluation Based on Case Studies. Chemical Geology, 93, 105-118.

https://doi.org/10.1016/0009-2541(90)90143-U 
Makishima, A., \& Nakamura, E. (1997). Suppression of Matrix Effects in ICP-MS by High Power Operation of ICP: Application to Precise Determination of Rb, Sr, Y, Cs, Ba, Ree, $\mathrm{Pb}$, Th and $\mathrm{U}$ at $\mathrm{ng} \mathrm{g}^{-1}$ Levels in Milligram Silicate Samples. Geostandards Newsletter, 21, 307-319. https://doi.org/10.1111/j.1751-908X.1997.tb00678.x

Makishima, A., \& Nakamura, E. (2006). Determination of Major, Minor and Trace Elements in Silicate Samples by ICP-QMS and ICP-SFMS Applying Isotope Dilution-Internal Standardisation (ID-IS) and Multi-Stage Internal Standardisation. Geostandards and Geoanalytical Research, 30, 245-271.

https://doi.org/10.1111/j.1751-908X.2006.tb01066.x

Makishima, A., Nakamura, E., \& Nakano, T. (1997). Determination of Boron in Silicate Samples by Direct Aspiration of Sample HF Solutions into ICPMS. Analytical Chemistry, 69, 3754-3759. https://doi.org/10.1021/ac970383s

Makishima, A., Tanaka, R., \& Nakamura, E. (2009). Precise Elemental and Isotopic Analyses in Silicate Samples Employing ICP-MS: Application of Hydrofluoric Acid Solutions and Analytical Techniques. Analytical Sciences, 25, 1181-1187.

https://doi.org/10.2116/analsci.25.1181

Olesik, J. W., \& Jiao, S. (2017). Matrix Effects Using an ICP-MS with a Single Positive Ion Lens and Grounded Stop: Analyte Mass Dependent? Journal of Analytical and Atomic Spectrometry, 32, 951-966. https://doi.org/10.1039/C7JA00043J

Pace, H. E., Rogers, N. J., Jarolimek, C., Coleman, V. A., Higgins, C. P., \& Ranville, J. F. (2011). Determining Transport Efficiency for the Purpose of Counting and Sizing Nanoparticles via Single Particle Inductively Coupled Plasma Mass Spectrometry. Analytical Chemistry, 83, 9361-9369. https://doi.org/10.1021/ac201952t

Panteeva, S., Gladkochoub, D., Donskaya, T., Markova, V., \& Sandimirova, G. (2003). Determination of 24 Trace Elements in Felsic Rocks by Inductively Coupled Plasma Mass Spectrometry after Lithium Metaborate Fusion. Spectrochimica Acta B, 58, 341-350. https://doi.org/10.1016/S0584-8547(02)00151-9

Pi, J.-L., You, C.-F., \& Chung, C.-H. (2014). Micro-Sublimation Separation of Boron in Rock Samples for Isotopic Measurement by MS-ICPMS. Journal Analytical Atomic Spectrometry, 29, 861-867. https://doi.org/10.1039/C3JA50344E

Potts, P. J. (1987). Inductively Coupled Plasma-Mass Spectrometry. In A Handbook of Silicate Rock Analysis (pp. 575-586, 610). Glasgow: Blackie, Chapman and Hall.

Potts, P. J., Webb, P. C., \& Thompson, M. (2013). An Assessment of Performance in the Routine Analysis of Silicate Rocks Based on Analysis of Data Submitted to the GeoPT Proficiency Testing Programme for Geochemical Laboratories (2001-2011). Geostandards and Geoanalytical Research, 37, 403-416. https://doi.org/10.1111/j.1751-908X.2013.00216.x

Potts, P. J., Webb, P. C., \& Thompson, M. (2015). Bias in the Determination of Zr, Y, and Rare Earth Element Concentrations in Selected Silicate Rocks by ICP-MS When Using Some Routine Acid Dissolution Procedures: Evidence from the GeoPT Proficiency Testing Programme. Geostandards and Geoanalytical Research, 39, 315-327. https://doi.org/10.1111/j.1751-908X.2014.00305.x

Pretorius, W., Weis, D., Williams, G., Hanano, D., Kieffer, B., \& Scoates, B. (2006). Complete Trace Element Characterisation of Granitoid (USGS G-2, GSP-2) Reference Materials by High Resolution Inductively Coupled Plasma-Mass Spectrometry. Geostandards and Geoanalytical Research, 30, 39-54. https://doi.org/10.1111/j.1751-908X.2006.tb00910.x

Robinson, P., Townsend, A. T., Yu, Z., \& Münker, C. (2006). Determination of Scandium, Yttrium and Rare Earth Elements in Rocks by High Resolution Inductively Coupled 
Plasma-Mass Spectrometry. Geostandards Newsletter, 23, 31-46. https://doi.org/10.1111/j.1751-908X.1999.tb00557.x

Schudel, G., Lai, V., Gordon, K., \& Weis, D. (2015). Trace-Element Characterization of USGS Reference Materials by HR-ICP-MS and Q-ICP-MS. Chemical Geology, 410, 223-236. https://doi.org/10.1016/j.chemgeo.2015.06.006

Shibata, N., Fudagawa, N., \& Kubota, M. (1991). Electrothermal Vaporizarion Using a Tungsten Furnace for the Determination of Rare-Earth Elements by Inductively Coupled Plasma Mass Spectrometry. Analytical Chemistry, 63, 636-640. https://doi.org/10.1021/ac00006a016

Sine, N. M., Taylor, W. O., Webber, G. R., \& Lewis, C. L. (1969). Third Report of Analytical Data for CAAS Sulphide Ore and Syenite Rock Standards. Geochimica et Cosmochimica Acta, 33, 121-131. https://doi.org/10.1016/0016-7037(69)90095-7

Ślachciński, M. (2018). Slurry Micro-Sampling Technique for Use in Argon-Helium Microwave Induced Plasma Optical Spectrometry. Talanta, 161, 812-818. https://doi.org/10.1016/j.talanta.2016.09.043

Smirnova, E., Fedorova, I., Sandimirova, G., Petrov, L., Balbekina, N., \& Lozhkin, V. (2003). Determination of Rare Earth Elements in Black Shales by Inductively Coupled Mass Spectrometry. Spectrochimica Acta B, 58, 329-340. https://doi.org/10.1016/S0584-8547(02)00152-0

Tan, S. H., \& Horlick, G. (1987). Matrix-Effect Observations in Inductively Coupled Plasma Mass Spectrometry. Journal of Analytical Atomic Spectrometry, 2, 745-763. https://doi.org/10.1039/ja9870200745

Tanaka, R., Makishima, A., Kitagawa, H., \& Nakamura, E. (2003). Suppression of Zr, Nb, $\mathrm{Hf}$, and Ta Coprecipitation in Fluoride Compounds for Determination of Ca-Rich Materials. Journal Analytical Atomic Spectrometry, 18, 1458-1463. https://doi.org/10.1039/b309948b

Townsend, A. T. (2000). The Accurate Determination of the First Row Transition Metals in Water, Urine, Tissue and Rock Samples by Sector Field ICP-MS. Journal Analytical Atomic Spectrometry, 15, 307-314. https://doi.org/10.1039/a904933i

Wilbur, S. (2007). Rapid Analysis of High-Matrix Environmental Samples Using the Agilent 7500cx ICP-MS. Agilent Technologies, Agilent Applications 5989-7297EN.

Willbold, M., Jochum, K. F., Raczek, I., Amini, M. A., Stoll, B., \& Hofmann, A. W. (2003). Validation of Multi-Element Isotope Dilution ICPMS for the Analysis of Basalts. Analytical and Bioanalytical Chemistry, 377, 117-125. https://doi.org/10.1007/s00216-003-2037-4

Wood, S. (2008). Using Reference Materials to Establish Metrological Traceability (2 p.). European Reference Materials, Application Note 3. http://www.erm-crm.org

Yokoyama, T., Makishima, A., \& Nakamura, E. (1999). Evaluation of the Coprecipitation of Incompatible Trace Elements with Fluoride during Silicate Rock Dissolution by Acid Digestion. Chemical Geology, 157, 175-187. https://doi.org/10.1016/S0009-2541(98)00206-X

Yokoyama, T., Nagai, Y., Hinohara, Y., \& Mori, T. (2016). Investigating the Influence of Non-Spectral Matrix Effects in the Determination of Twenty-Two Trace Elements in Rock Samples by ICP-QMS. Geostandards and Geoanalytical Research, 41, 221-242. https://doi.org/10.1111/ggr.12147 